\title{
Numerical Simulation Research on Response Characteristics of Grouting Defects of Ground Penetrating Radar for Detection of Grouting Quality behind Tunnel Wall
}

\author{
D.Michelle Naomie Mavoungou1,2, Pingsong Zhang1,2*, Siwei Zhang², Qiong Wang² \\ ${ }^{1}$ State key laboratory of mining response and disaster prevention and control in deep coal mines, Huainan 232001, China
} ${ }^{2}$ School of Earth and Environment, Anhui University of Science and Technology, Huainan 232001, China

*Corresponding author: Pingsong Zhang, pszhang1971@163.com

\begin{abstract}
The effect of grouting behind tunnel wall directly affects the surrounding ground settlement and the stability of tunnel structure, so the grouting quality detection is very necessary. As an efficient and convenient shallow geophysical exploration method, ground-penetrating radar can meet the high-resolution and non-destructive requirements of grouting quality detection behind the tunnel wall, so it is widely used in engineering in recent years. Most of the existing studies have obvious regional pertinence and special geological conditions, and there are few universal studies on the characteristics of the ground penetrating radar reflection image of the grouting defect behind the tunnel wall. In view of this, this paper uses the finite difference time domain method to simulate several grouting defects behind the wall, such as voids, water-bearing anomaly, cracks, and other grouting defects. The simulation results show that the reflection image of the direct wave is characterized by a white band with strong amplitude; the interface between primary support and second lining, primary support, and surrounding rock is also banded; the circular cavity and water anomaly characteristics are all hyperbolic, the difference is that the phase of the lower part of the radar image of the cavity anomaly is 0 , and there are only hyperbolic tails on both sides, and the water-bearing anomaly also has obvious hyperbolic characteristics at each interface; the reflected wave characteristics of the rectangular crack are striped and watery and the reflected wave characteristic of rectangular cracks is striped, and the abnormal range of water-bearing cracks on the radar image is larger than that of air. The research results can provide an effective theoretical reference for the engineering application of ground penetrating radar detection of grouting defects behind the tunnel wall.
\end{abstract}

Keywords: Grouting behind the wall; Quality detection; GPR; Numerical simulation

Publication date: July 2021; Online publication: July 31, 2021

\section{Introduction}

With the rapid development of China's social economy, more and more road tunnels are being constructed. However, due to various reasons such as tunnel construction technology, construction environment, supervision efforts, and other reasons, most tunnels will inevitably have geological abnormalities such as cavities, water-bearing anomaly, and cracks behind concrete walls. In engineering, grouting is generally used to reinforce and treat them. Therefore, the detection of grouting quality is very important. Commonly used methods of grouting quality detection include analytical method, detection hole method, and acoustic monitoring method ${ }^{[1-3]}$, but these methods all require excavation and drilling, which requires a large amount of work and is time-consuming and labor-intensive. As an efficient and convenient geophysical detection 
method, ground penetrating radar has significant advantages such as fast and non-destructive detection. Numerical simulation method is the main method of geophysical exploration research.

The synthetic exploration records of numerical simulation calculation can be used for the design and evaluation of field observation system, test the advantages and disadvantages of various data processing methods and inversion methods, verify the correctness of interpretation conclusions, and provide effective theoretical guidance for practical engineering application. In view of this, many scholars at home and abroad have carried out a lot of numerical simulation research based on GPR technology. Chunjin Lin, Xiongyao Xie et al. ${ }^{[4-5]}$ used finite difference time domain (FDTD) to carry out numerical experiments on ground penetrating radar detection forward simulation and back-projection imaging, and established the ground penetrating radar detection interpretation criteria for typical lining diseases; Mingzhou Bai et al. ${ }^{[6]}$ studied the typical radar image characteristics of different types of karst caves and soil caves by combining numerical simulation and model test, taking the karst area in the eastern section of Beijing Shanghai highspeed railway as the experimental area, and proposed the method and characteristic standard of using ground penetrating radar method to determine the grouting effect. Furthermore, Huang Hongwei et al. ${ }^{[7-9]}$ conducted simulation experiments on the ground penetrating radar detection target behind the soft soil shield tunnel segments, and found that the age, distribution shape, and composition ratio of the grouting material can be used to detect the GPR profile. The figure has a significant impact, as Zeng Chenchao et al. ${ }^{[10]}$ conducted a ground penetrating radar forward simulation on two typical working conditions of uneven grouting behind the tunnel lining wall and tunnel segment cracks and used the consistency elimination method to process the simulation data, and successfully obtained the radar image characteristics of the two working conditions. However, most of the existing research results have obvious regional pertinence and special geological conditions, and there are few general studies on the characteristics of the ground penetrating radar reflection image characteristics of the grouting defect behind the tunnel wall.

On the basis of summarizing the previous research methods and achievements, this paper designs three kinds of abnormal conditions that may exist after grouting in the tunnel wall, which are cavity defect, waterbearing defect and crack defect. The finite element difference method is used to simulate the three kinds of abnormal conditions, and the GPR response characteristics and laws are summarized, the superiority of GPR in detecting the structural integrity of concealed engineering body is verified, which lays the foundation for the follow-up research and has certain application value.

\section{Basic principle of ground penetrating radar}

As a geophysical detection method, ground penetrating radar (GPR) ${ }^{[11-13]}$ has been widely used in the engineering field with remarkable effect. The geophysical basis of its detection is the difference of electrical parameters between the target and the surrounding medium (including dielectric constant, conductivity, permeability, etc.). The working principle is that the GPR transmitting antenna emits a high-frequency pulse electromagnetic wave $(20 \mathrm{MHz}-2 \mathrm{GHz})$. When the high-frequency electromagnetic wave propagates downward and meets the interface with a large difference in dielectric constant, it will reflect and refract. We can get the internal structure information of the target by analyzing the scattered wave image. Figure 1. is a schematic diagram of the working principle of GPR.

In detecting the quality and defects of concealed engineering structures, ground penetrating radar has a good application effect ${ }^{[14-16]}$. In this paper, $800 \mathrm{MHz}$ ground penetrating radar is used to finely detect grouting defects behind the tunnel wall, and the radar image characteristics of different defects are summarized. Figure 2. shows how the ground penetrating radar detects geological anomalies behind the concrete wall. 


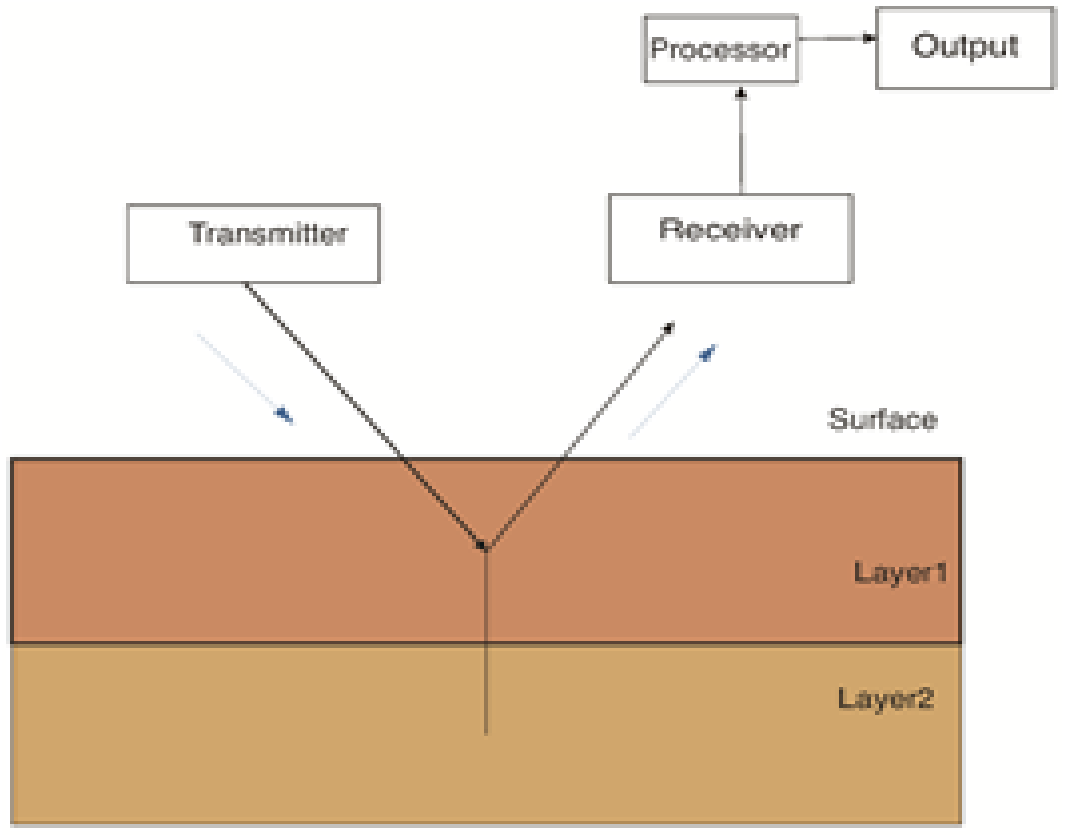

Figure 1. Working principle of GPR

AAE Rocolver Antonna

TA: Trasmitior Antenna

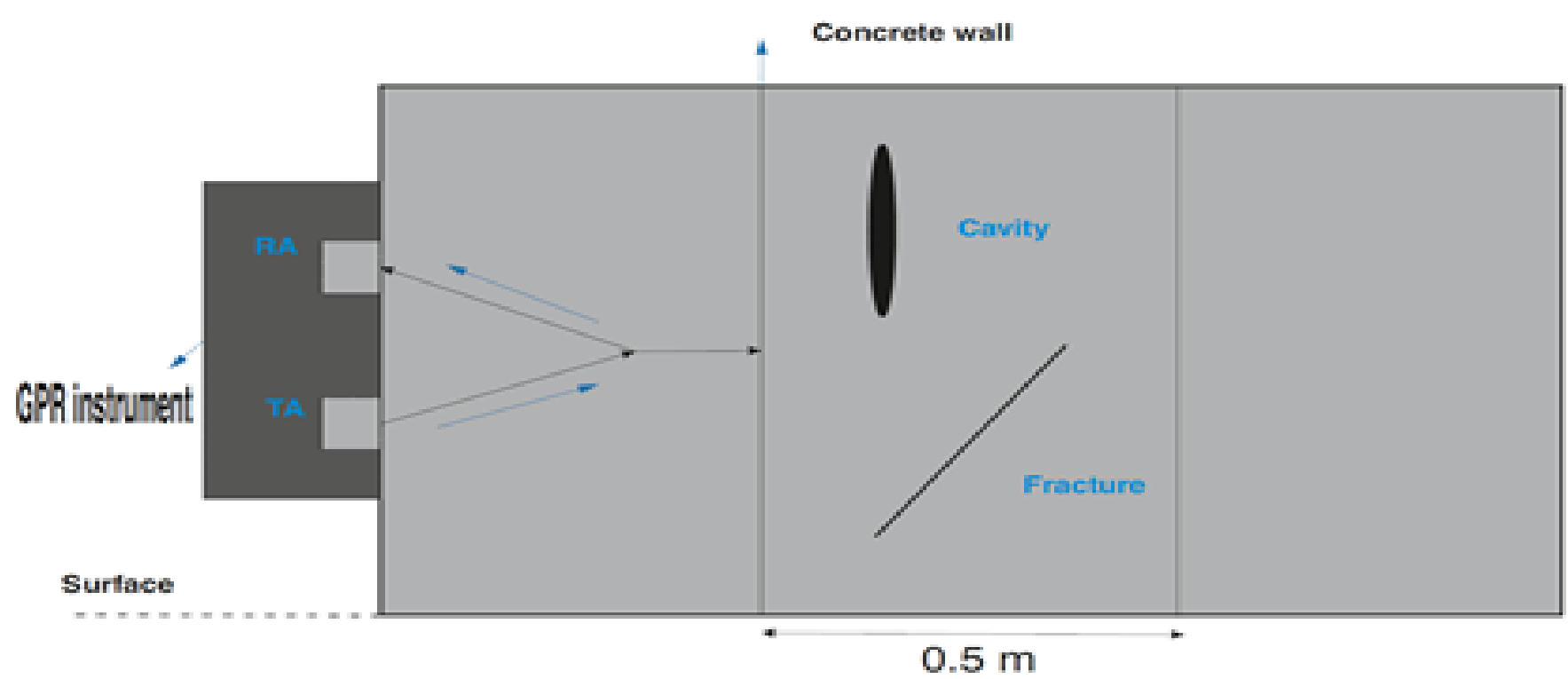

Figure 2. Use of ground penetrating radar method behind concrete wall of tunnel to detect geological abnormalities with high resolution

\section{Numerical Simulation}

\subsection{Numerical simulation method}

Ground penetrating radar is a shallow geophysical exploration method that detects the internal structural integrity of concealed engineering body according to the difference of electromagnetic properties of different media by transmitting high-frequency pulse electromagnetic wave and receiving the reflection wave of underground media [17]. According to the theory of electromagnetic wave propagation, the propagation of high-frequency pulse electromagnetic wave emitted by GPR obeys Maxwell equations. Maxwell's equations are composed of electromagnetic induction law and Ampere's circulation law, which 
are the basic methods to describe electromagnetic fields.

The difference time domain method ${ }^{[18]}$ is a method based on Maxwell's equations to calculate electromagnetic waves, which was proposed by K.S.Yee ${ }^{[19]}$. He divided the simulated electromagnetic space into finite grids and solved the electromagnetic field value in the whole simulation space through the electromagnetic field in a single grid.

The basic equation of FDTD method is as follows :-

$$
\left\{\begin{array}{c}
\frac{\partial H_{z}}{\partial y}-\frac{\partial H_{y}}{\partial z}=\varepsilon \frac{\partial E_{x}}{\partial t}+\partial E_{x} \\
\frac{\partial H_{x}}{\partial z}-\frac{\partial H_{z}}{\partial x}=\varepsilon \frac{\partial E_{y}}{\partial t}+\partial E_{y} \\
\frac{\partial H_{y}}{\partial x}-\frac{\partial H_{x}}{\partial y}=\varepsilon \frac{\partial E_{z}}{\partial t}+\partial E_{z} \\
\frac{\partial H_{z}}{\partial y}-\frac{\partial E_{y}}{\partial z}=-\mu \frac{\partial H_{x}}{\partial t}-\sigma_{m} H_{x} \\
\frac{\partial H_{x}}{\partial z}-\frac{\partial E_{z}}{\partial x}=-\mu \frac{\partial H_{y}}{\partial t}-\sigma_{m} H_{y} \\
\frac{\partial H_{y}}{\partial x}-\frac{\partial E_{X}}{\partial y}=-\mu \frac{\partial H_{z}}{\partial t}-\sigma_{m} H_{z}
\end{array}\right.
$$

In the equations, $\mathrm{H}$ is the magnetic field intensity $(\mathrm{A} / \mathrm{m}) ; \varepsilon$ is the dielectric constant; $\mathrm{E}$ is the electric field intensity $(\mathrm{V} / \mathrm{m})$; $\sigma$ is the electrical conductivity; $\mu$ is the permeability; $\sigma \mathrm{m}$ is the magnetic permeability.

The GPR simulation results can be obtained by assigning the value of $E$ and $H$. The GPR obtains the scanning image of the section by the continuous drag of the antenna. According to the characteristics of the reflected wave signal on the scanning image, the anomaly including cavity, water content, and crack behind the lining and the distribution of steel bars and steel frame are identified. Then, the buried depth and position of different defects and steel bars and steel frames are calculated according to the time-depth conversion formula. Where, $\mathrm{h}$ is the depth of the target body; $\mathrm{t}$ is the two-way reflection time of target to radar wave.

Calculation formula :-

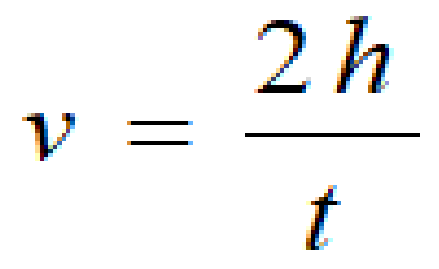

\subsection{Forward simulation and analysis}

The basic model is a rectangular area of $5 \mathrm{~m} \times 2 \mathrm{~m}$, and the model setting parameters are shown in Table 1. The grid step size $d x$ and dy of each model are both 0.01 , the time window is set to $18 \mathrm{~ns}$. The number of stacks is 480 , the center frequency of the antenna is $800 \mathrm{MHz}$, the starting position of the transmitting antenna is $(0.10,1.95)$, the transmitting and receiving distance is $0.05 \mathrm{~m}$, and the antenna moving step size along the horizontal direction is $0.01 \mathrm{~m}$. 
Table 1. Model setting parameters

\begin{tabular}{ccccc}
\hline Region & Medium & $\begin{array}{c}\text { Dielectric } \\
\text { constant }\end{array}$ & $\begin{array}{c}\text { Conducti-vity } \\
(\mathbf{s} / \mathbf{m})\end{array}$ & $\begin{array}{c}\text { Thickness } \\
(\mathbf{m})\end{array}$ \\
\hline Second lining & C35 concrete & 9 & 0.01 & 0.4 \\
Waterproof board & EVA & 3 & 0.01 & 0.01 \\
Initial support & C25 concrete & 8 & 0.01 & 0.25 \\
Surrounding rock & Limestone & 20 & 0.025 & 1.29 \\
cavity & Air & 1 & 0 & 0.1 \\
Water-bearing defect & Water & 81 & 0.01 & 0.1 \\
\hline
\end{tabular}

\subsubsection{Circular anomaly model}

The orange area at the bottom of the model is limestone, which is used to simulate the surrounding rock of the tunnel; The green area is the primary support, and the blue area is the secondary lining. Its dielectric constant is 8 and 9 respectively. There is a rectangular area in the middle with a dielectric constant of 3 and a thickness of only 0.01 , which is used to simulate the waterproof board between the primary support and the secondary lining.

\subsubsection{Single anomaly model}

The anomalies are all located at the same depth of the second lining, and their radius is $0.05 \mathrm{~m}$.

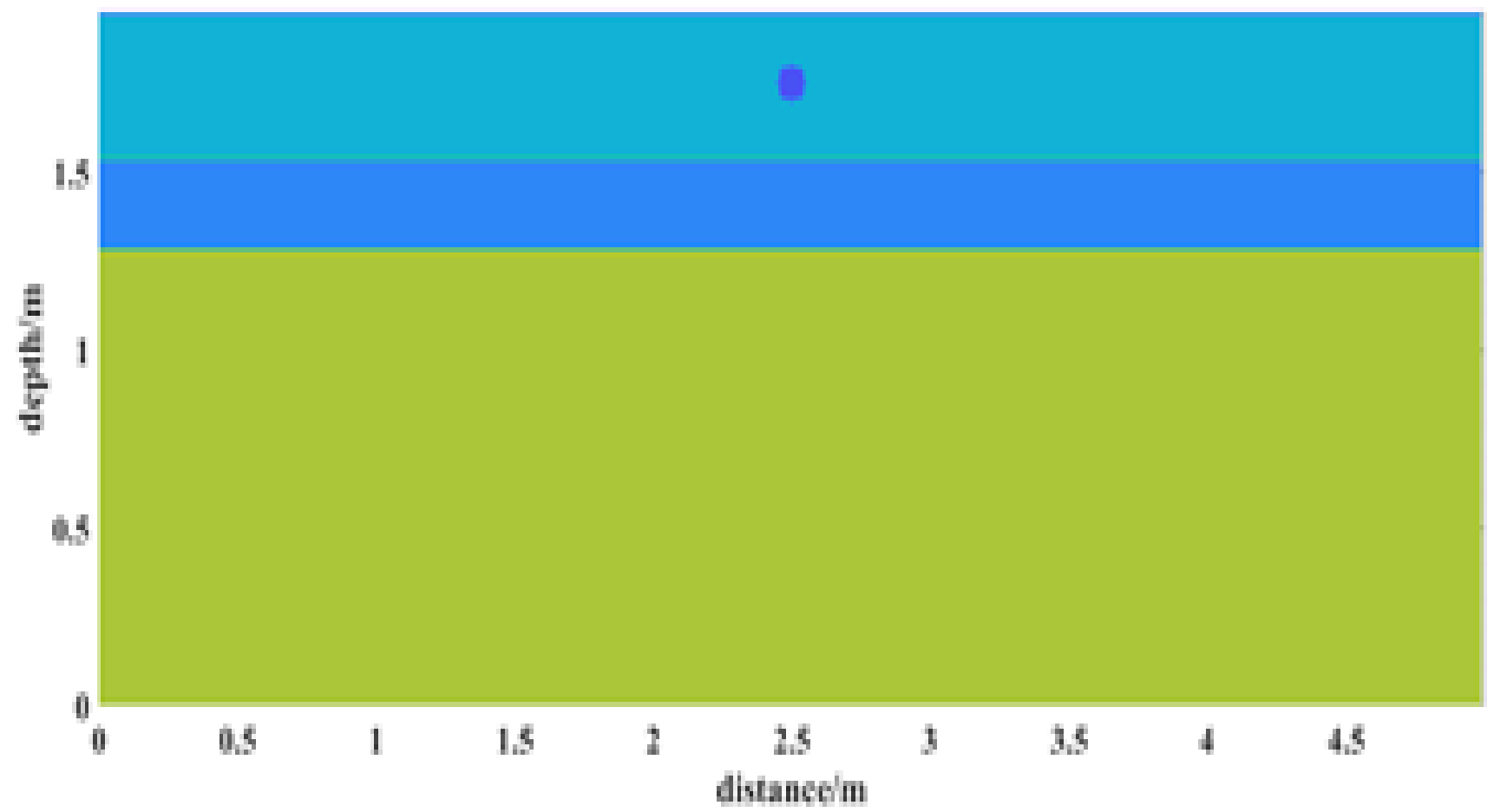

Figure 3. (a) Model 


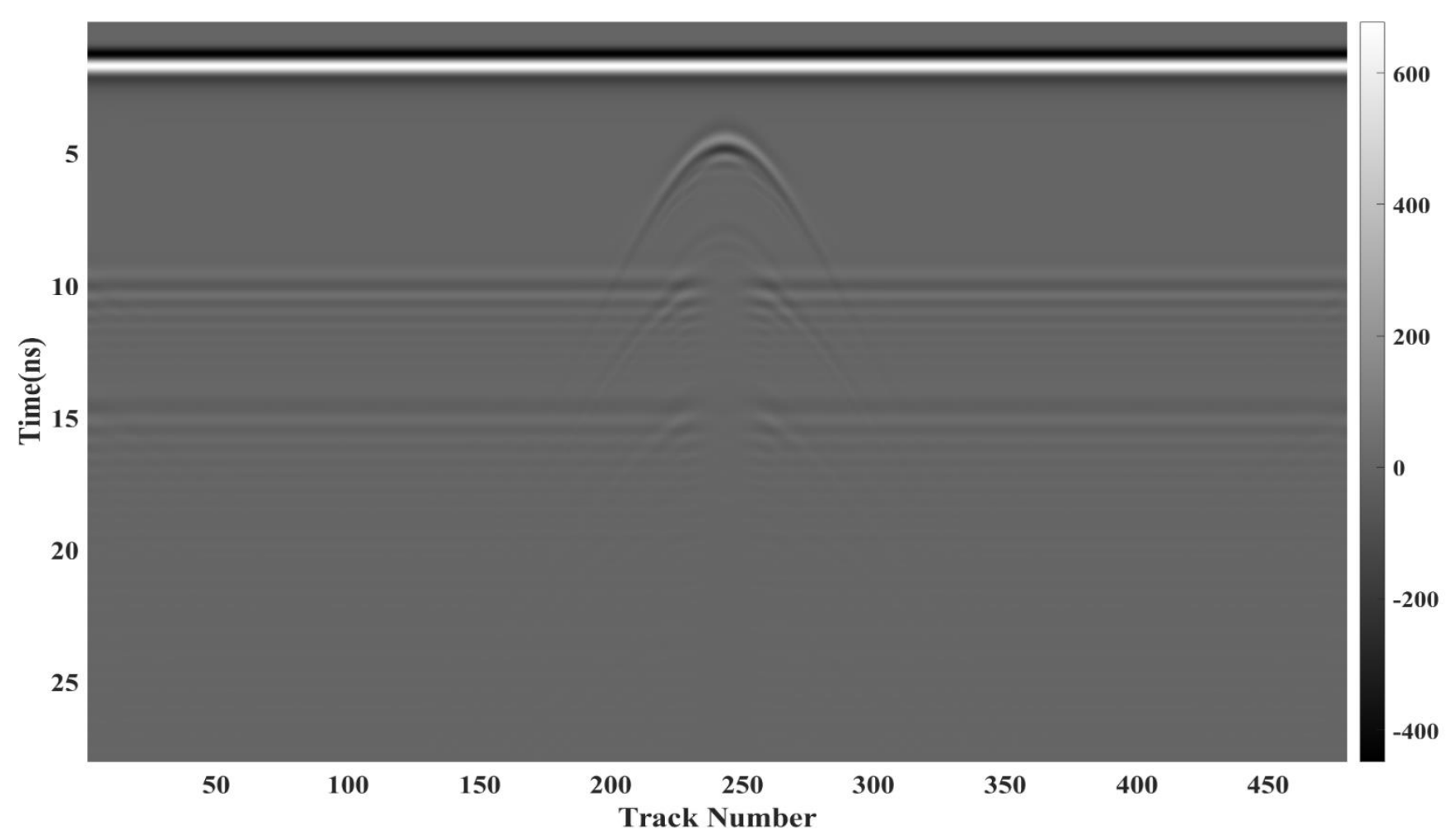

Figure 3. (b) Cavity response record

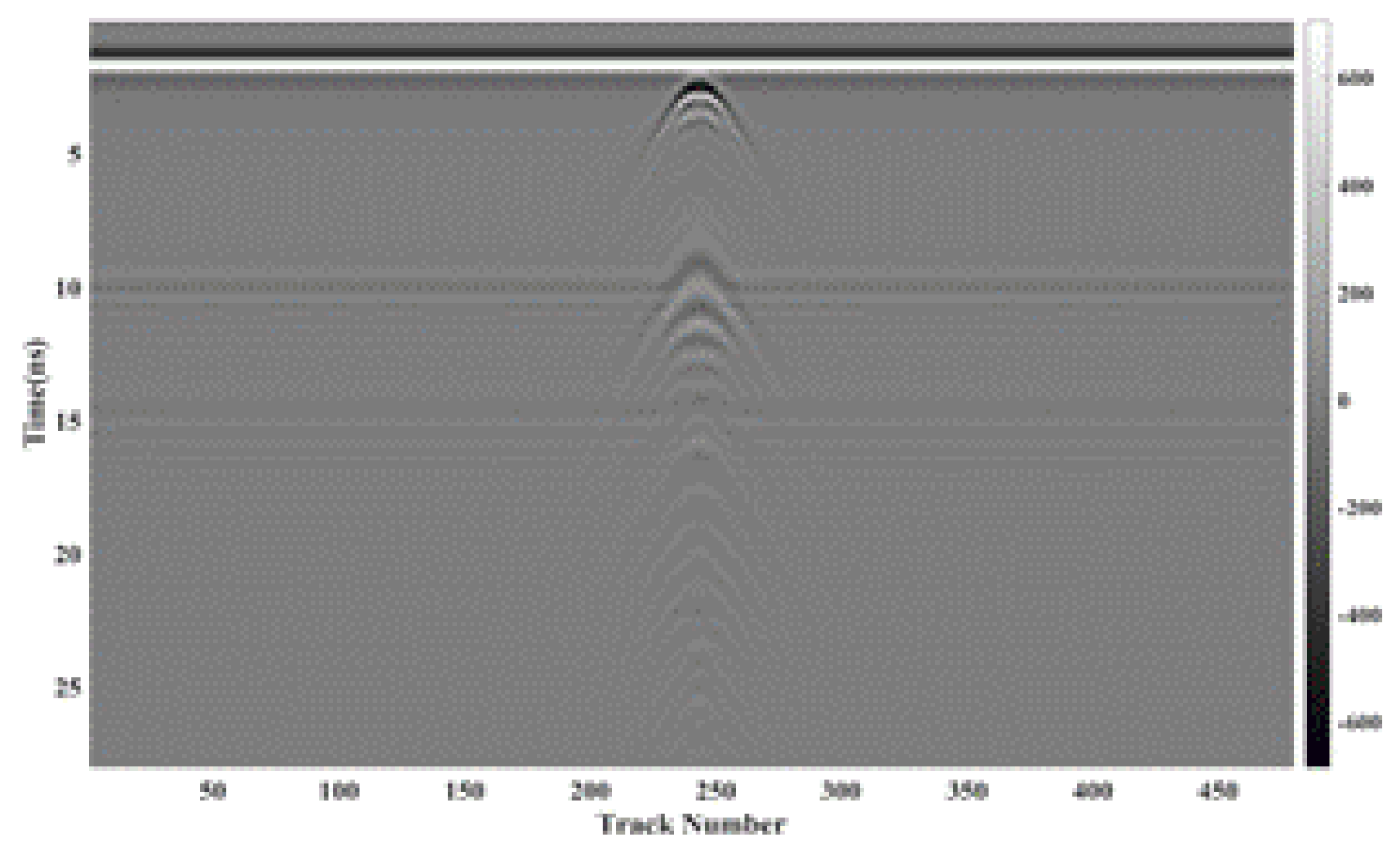

Figure 3. (c) Water-bearing anomaly response record

Figure 3. Forward diagrams of a single abnormal model 
It can be seen from Figure 3. (b) and Figure 3. (c) that when the circular anomalies are located at the same depth, the forward records are basically the same. The white strips in the figure are direct waves, and the cavities and water-bearing anomalies have hyperbolic reflection, as well as the interfaces between the secondary lining and the primary support, and between the primary support and the surrounding rock. The difference is that the phase of cavity anomaly is almost the same at 4ns, and there is no obvious multiple at the bottom, while the phase of water-bearing anomaly is quite different at $4 \mathrm{~ns}$, and there is multiple at the bottom. It is also different at the two interfaces. The interface in the hole record, that is, the phase corresponding to the top of the $4 \mathrm{~ns}$ reflection hyperbola is zero, and only the two ends have hyperbolic tails; while the two interfaces with anomalous water content have the reflection hyperbola is complete, and the top position of the arc is sharper than that at $4 \mathrm{~ns}$.

\subsubsection{Different depth models}

The abnormal coordinates from left to right are (1,1.29), (2,1.54), (3,1.75), (4,1.39), which are respectively located at the junction of the primary support and surrounding rock, the junction of the secondary lining and the primary support (i.e. the position of waterproof board), the second lining and the primary support, with radius of $0.05 \mathrm{~m}$.

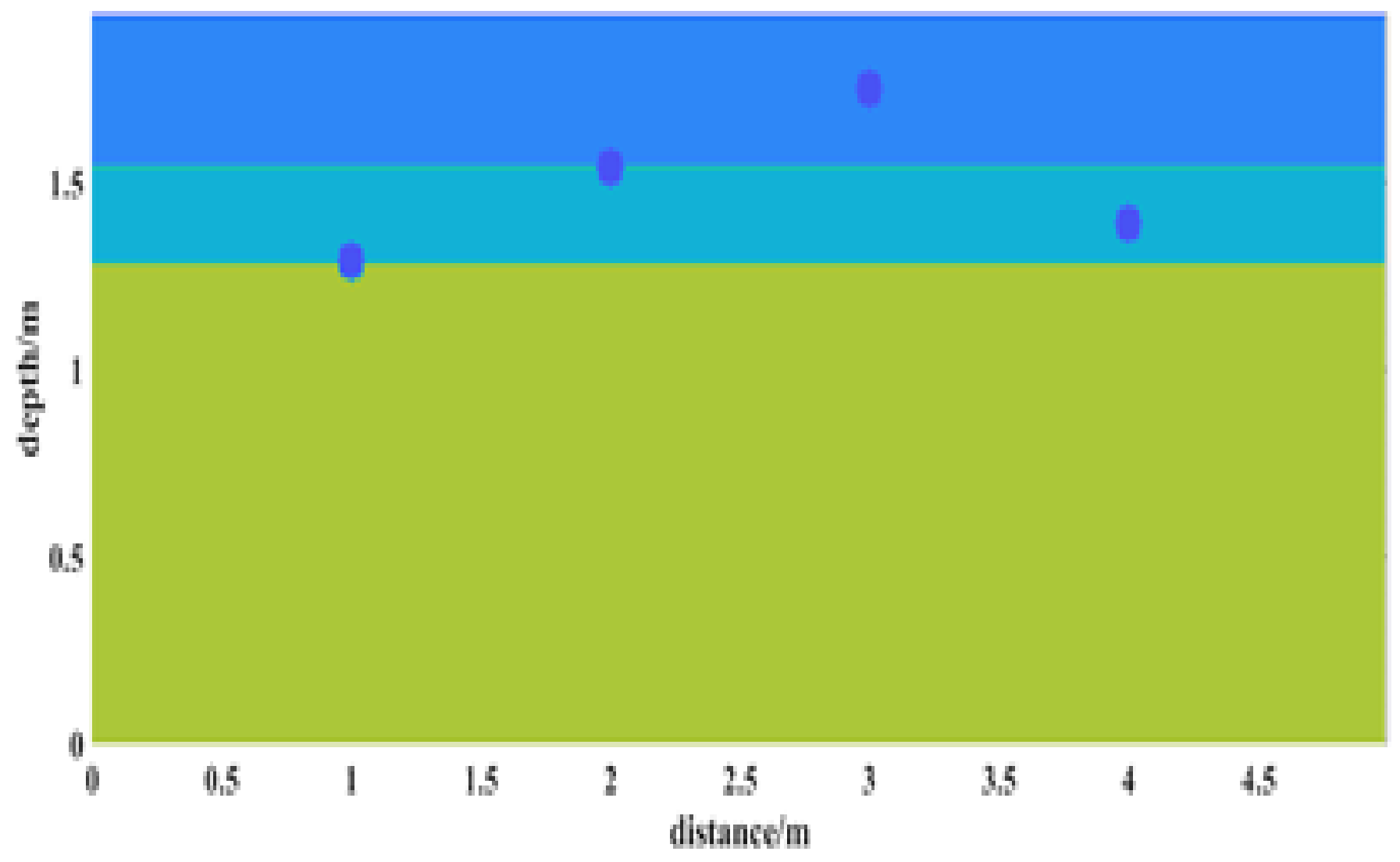

Figure 4. (a) Model 


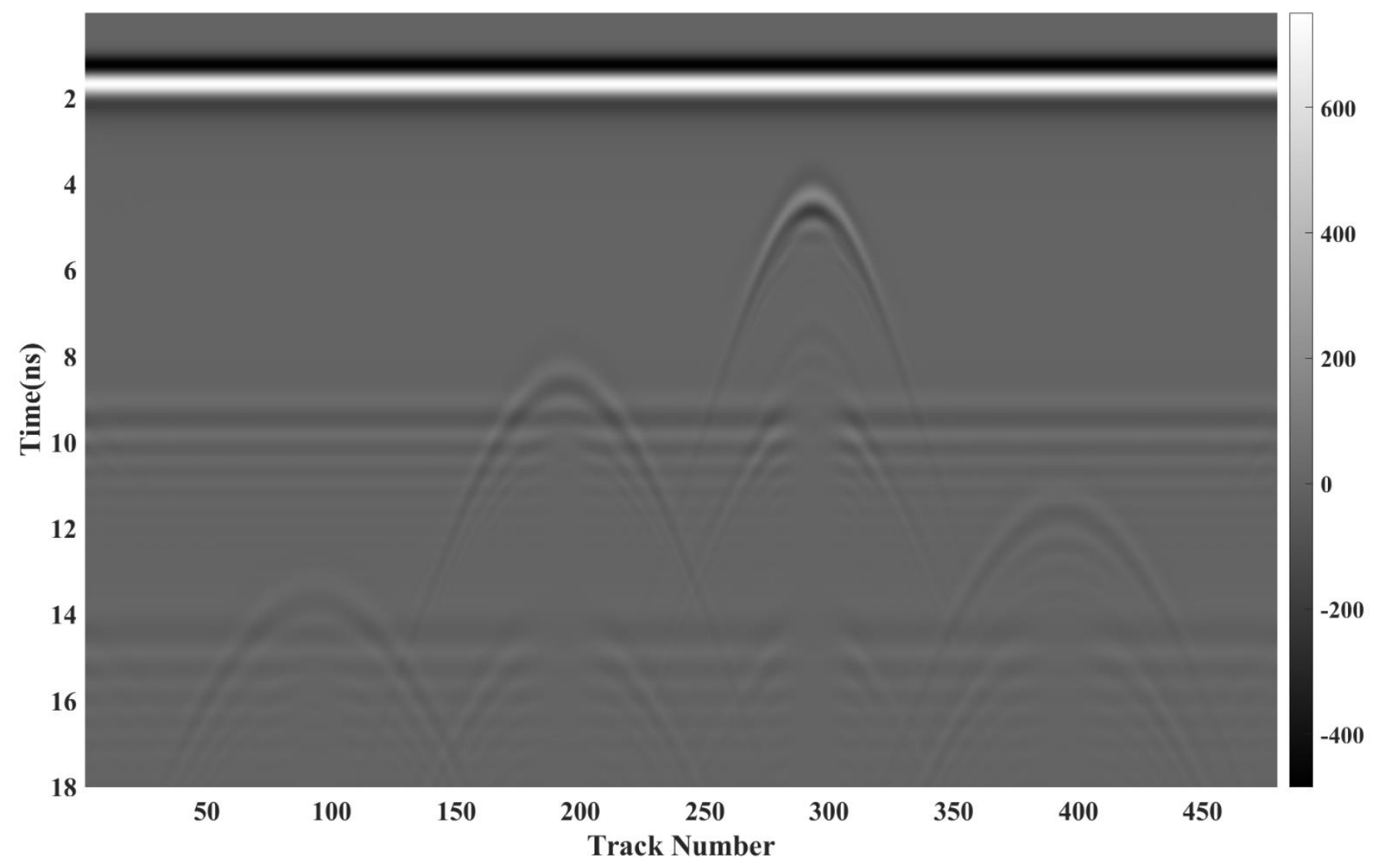

Figure 4. (b) Cavity response record

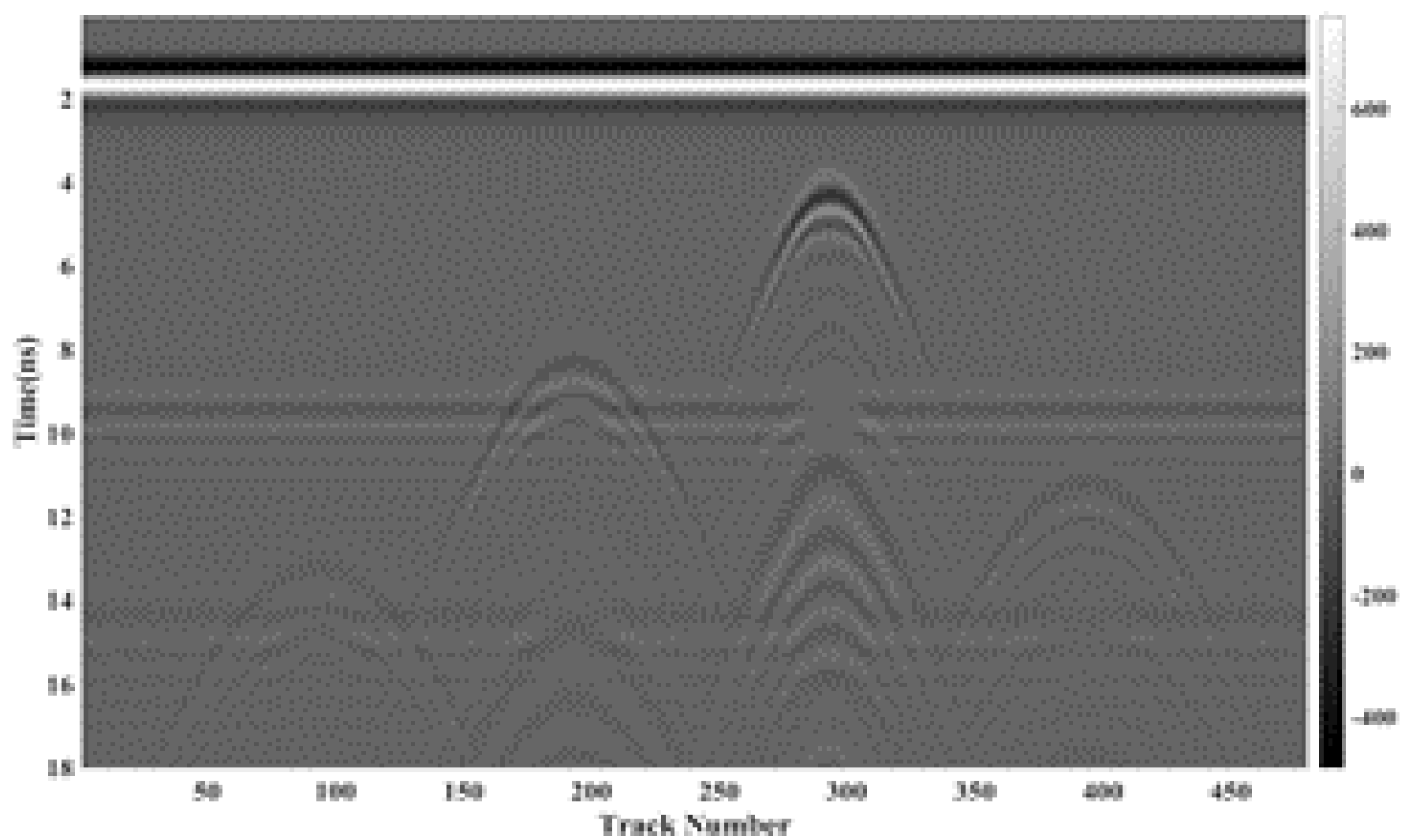

Figure 4. (c)Water-bearing anomaly response record

Figure 4. Forward diagrams of different depth models 
It can be seen from Figure 4. (b) and Figure 4. (c) that when the positions of circular anomalies are the same, the forward records are basically the same. The white strips in the figure are direct waves, and the cavities and water-bearing anomalies have hyperbolic reflection, and there are also interfaces between the secondary lining and the primary support, and the primary support and the surrounding rock. There are first reflected waves at $13 \mathrm{~ns}, 7 \mathrm{~ns}, 4 \mathrm{~ns}$, and $11 \mathrm{~ns}$ in the recording picture, which correspond to the circular anomalies of the model from left to right. The anomaly at the junction of the primary support and the surrounding rock is located below, and there is no interface at the lower part of the anomaly. There is only a group of reflection hyperbolas. The cavity record can only distinguish one hyperbola, while the waterbearing anomaly forward record can distinguish three hyperbolas; There is an interface between the primary support and the surrounding rock under the anomaly at the junction of the primary support and the second lining. There is a group of reflection hyperbolas at the corresponding lower position. The phase of the corresponding position of the cavity record arc top is 0 , and the water-bearing anomaly record can roughly distinguish the arc top; There are two groups of hyperbolas at the lower part of the cavity record, and the phase of the corresponding position of the arc top is 0 . In the water-bearing anomaly record, the hyperbolas are connected. The phase of the corresponding position of the interface between the primary support and the secondary lining is 0 , and there are hyperbolic tails at both ends. The hyperbolic arc top of the corresponding position of the primary support and the surrounding rock is obvious; The anomaly images in the initial branch are roughly the same, and the hyperbolic top at the interface is not obvious.

\subsubsection{Same depth model}

The 15 anomalies of the model are set at a depth of $0.2 \mathrm{~m}$, and the horizontal distance is $1.6-4.4 \mathrm{~m}$, and the interval is evenly distributed by $0.2 \mathrm{~m}$.

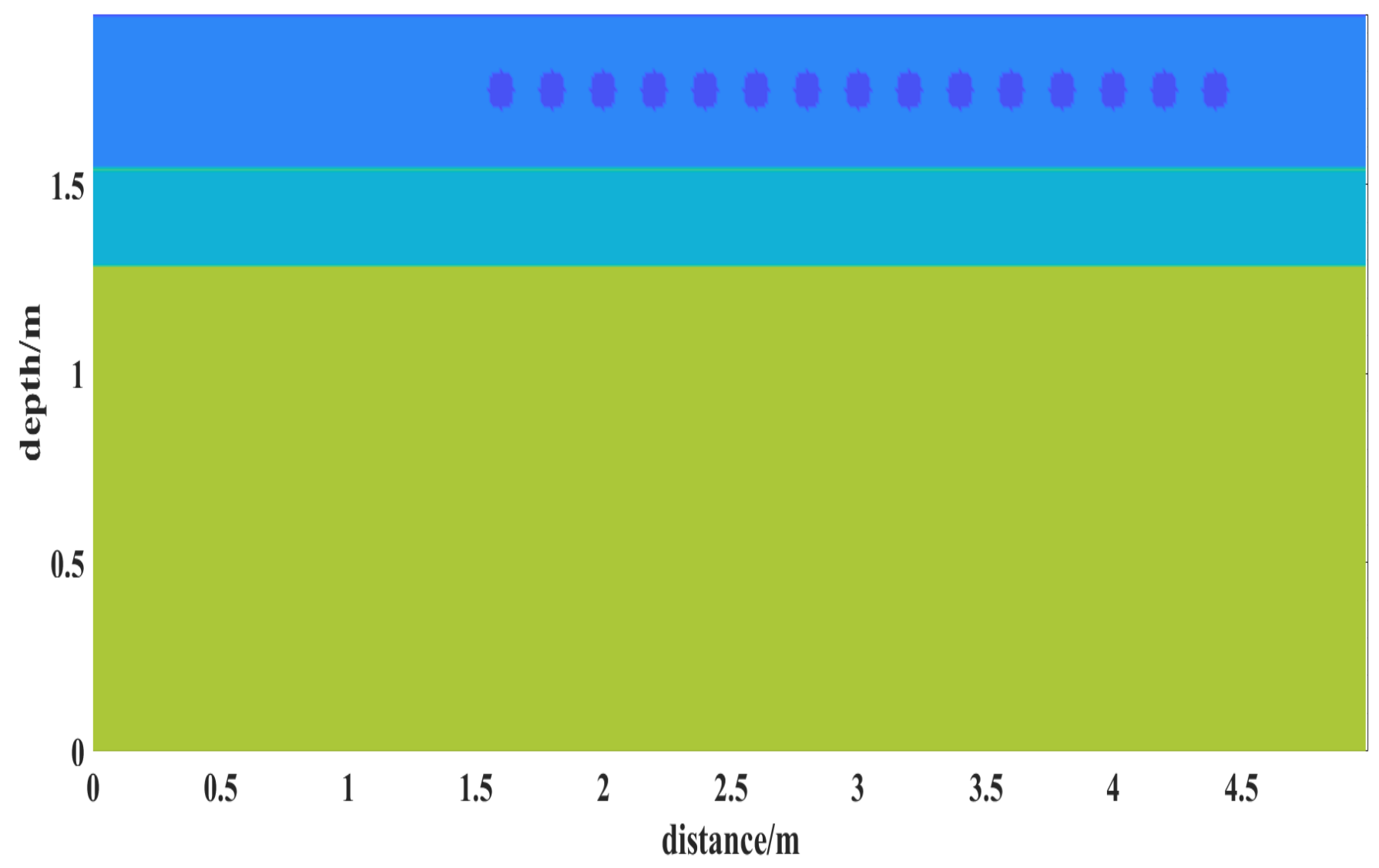

Figure 5. (a) Model 


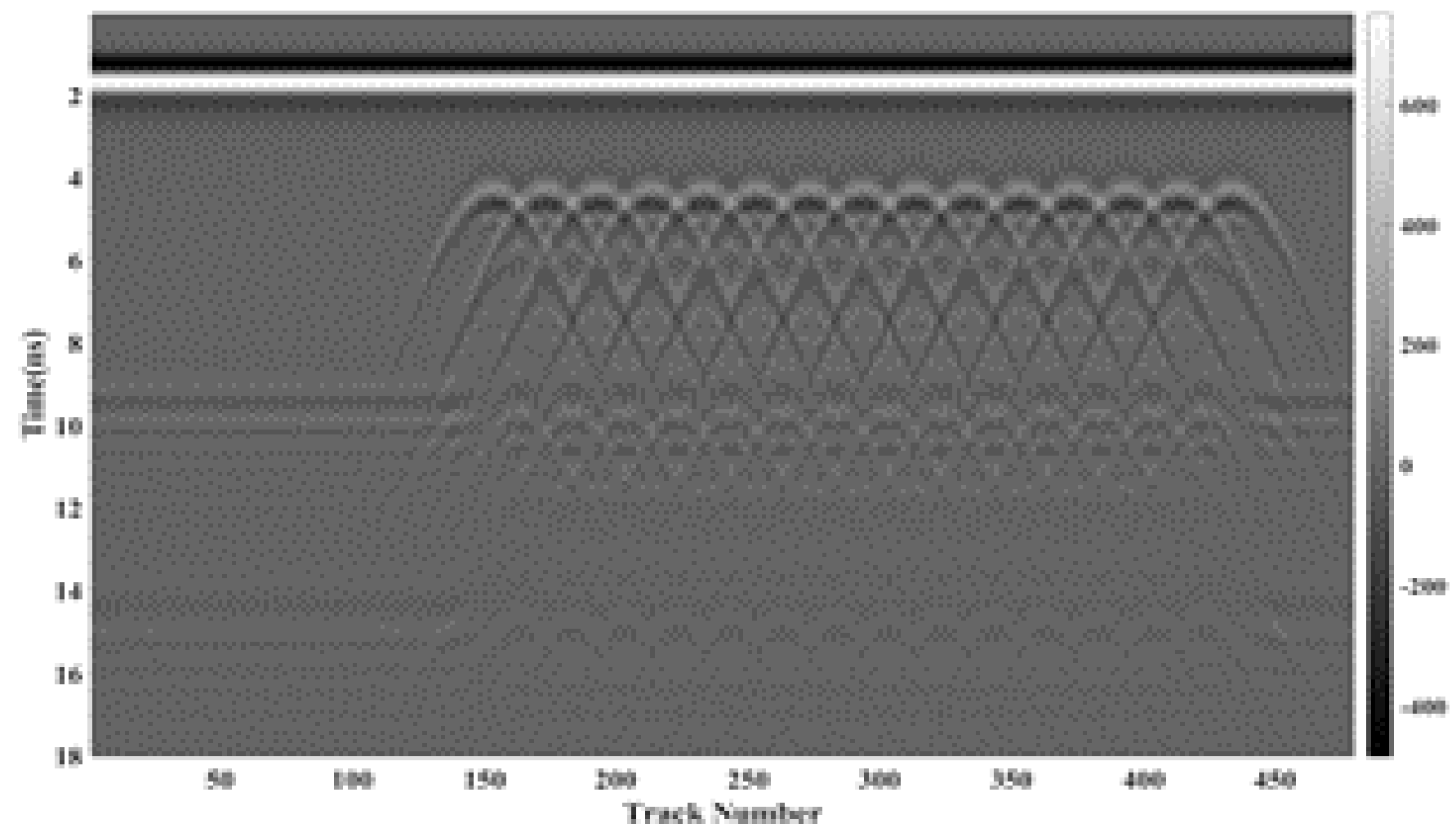

Figure 5. (b) Cavity response record

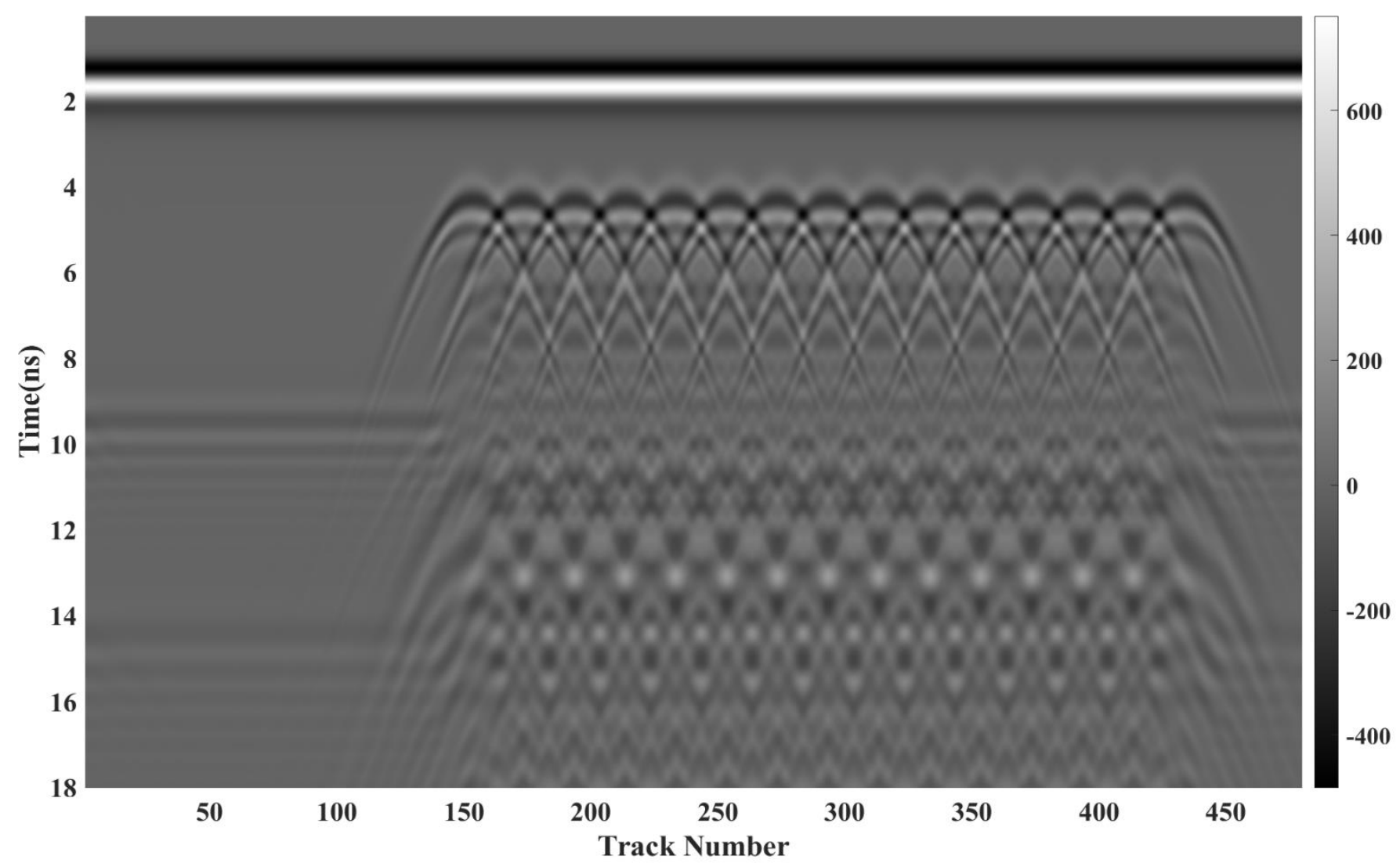

Figure 5. (c)Water-bearing anomaly response record

Figure 5. Forward diagrams of the same depth model 
It can be seen from the forward response records of GPR in Figure 5. (b) and Figure 5. (c) that the water-bearing anomaly is basically the same as the cavity anomaly. The white strips in the figure are direct waves, and the cavities and water-bearing anomalies have hyperbolic reflection, as well as the interfaces between the second lining and the primary support, and between the primary support and the surrounding rock. When the anomaly is located at the same depth and the size is the same, the anomaly area has a strong diffraction effect on the high-frequency electromagnetic wave, and obvious hyperbolas appear at the location of the anomaly, the diffraction hyperbolas generated by the adjacent diffraction points intersect, and high energy points are formed at and below the cavity ${ }^{[20-21]}$. The position of the upper arc top corresponds to the depth of the anomaly. There is a hyperbola formed by diffraction at the two interfaces. The difference is that below the interface between the primary support and the surrounding rock, the phase of the cavity is more consistent, while the water-bearing anomaly has larger fluctuations and multiple waves are more obvious.

\subsubsection{Water-bearing anomaly model with different lateral spacing}

The model is set as two water-bearing circular anomalies with different horizontal spacing, with a depth of $0.2 \mathrm{~m}$ and a radius of $0.05 \mathrm{~m}$. There are five models in this group, and the horizontal position coordinates and the spacing between the two anomalies are shown in Table 2.

Table 2. Coordinates and spacing of water-bearing anomalies

\begin{tabular}{ccc}
\hline $\begin{array}{c}\text { X-coordinate of water- bearing } \\
\text { anomaly }\end{array}$ & $\begin{array}{c}\text { X-coordinate of water- bearing } \\
\text { anomaly }\end{array}$ & Spacing (m) \\
\hline 1 & 4 & 3 \\
2 & 3 & 1 \\
2.3 & 2.7 & 0.4 \\
2.4 & 2.6 & 0.2 \\
2.45 & 2.55 & 0.1 \\
\hline
\end{tabular}

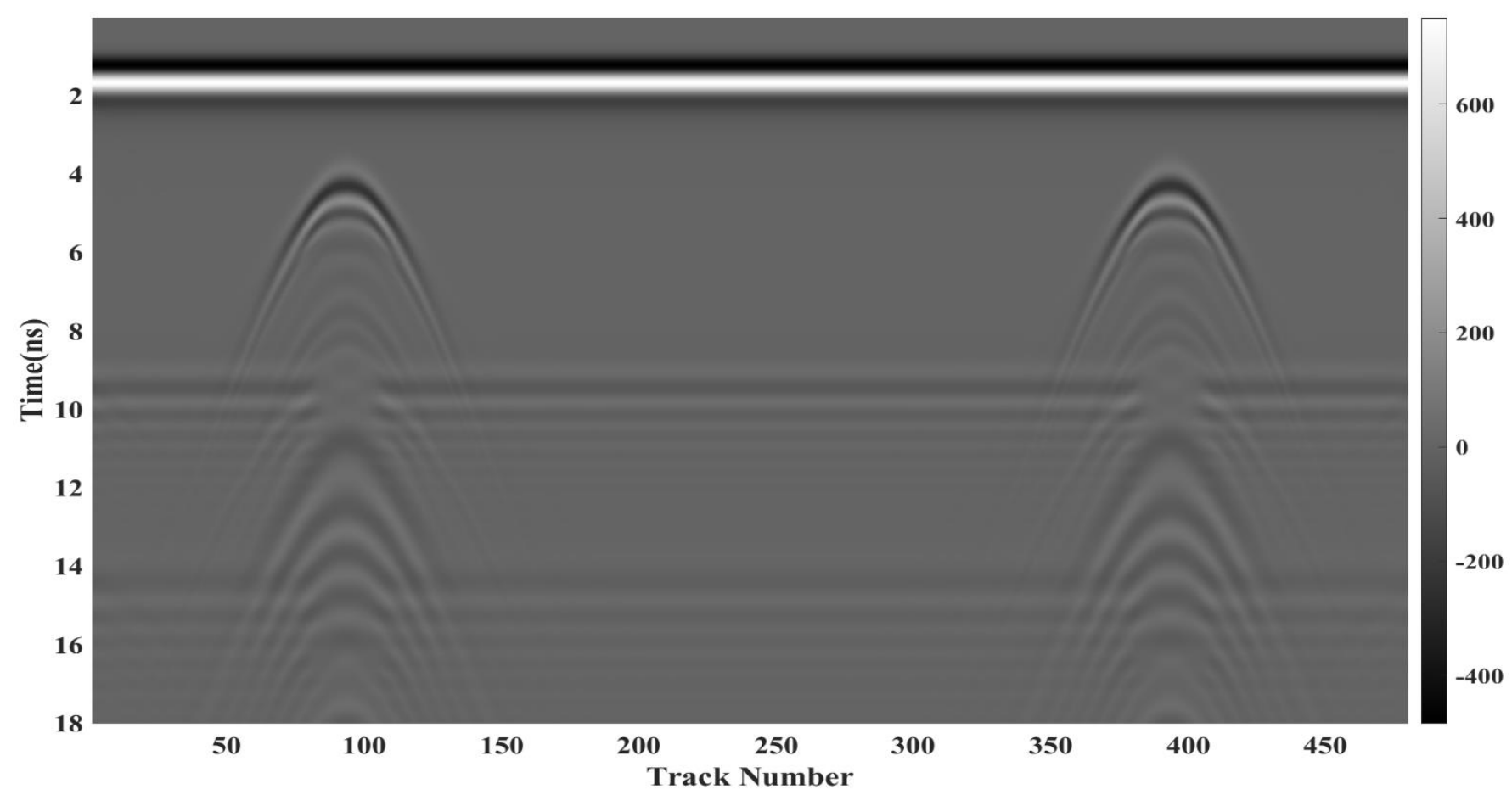

Figure 6. (a) $3 \mathrm{~m}$ interval 


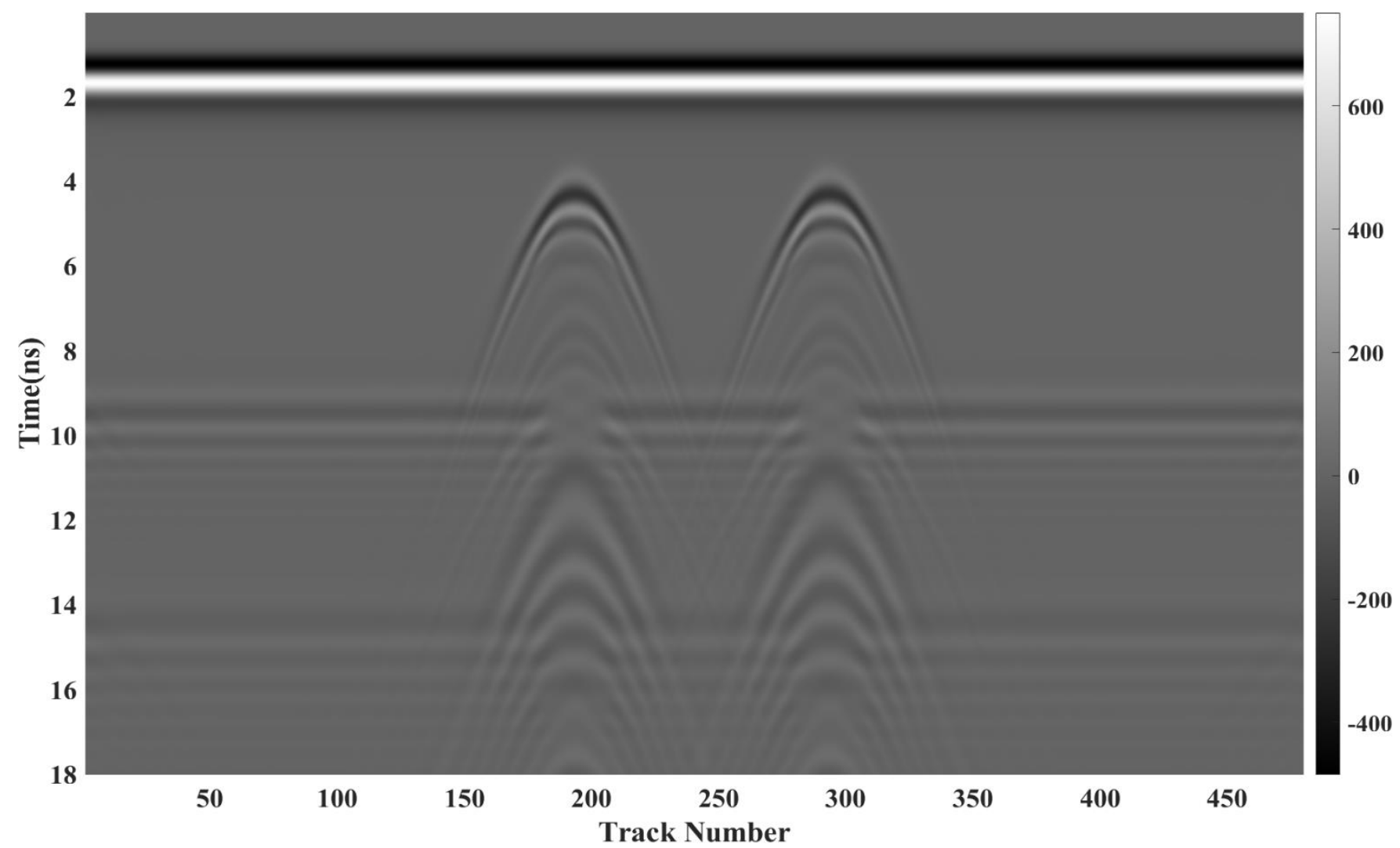

Figure 6. (b) $1 \mathrm{~m}$ interval

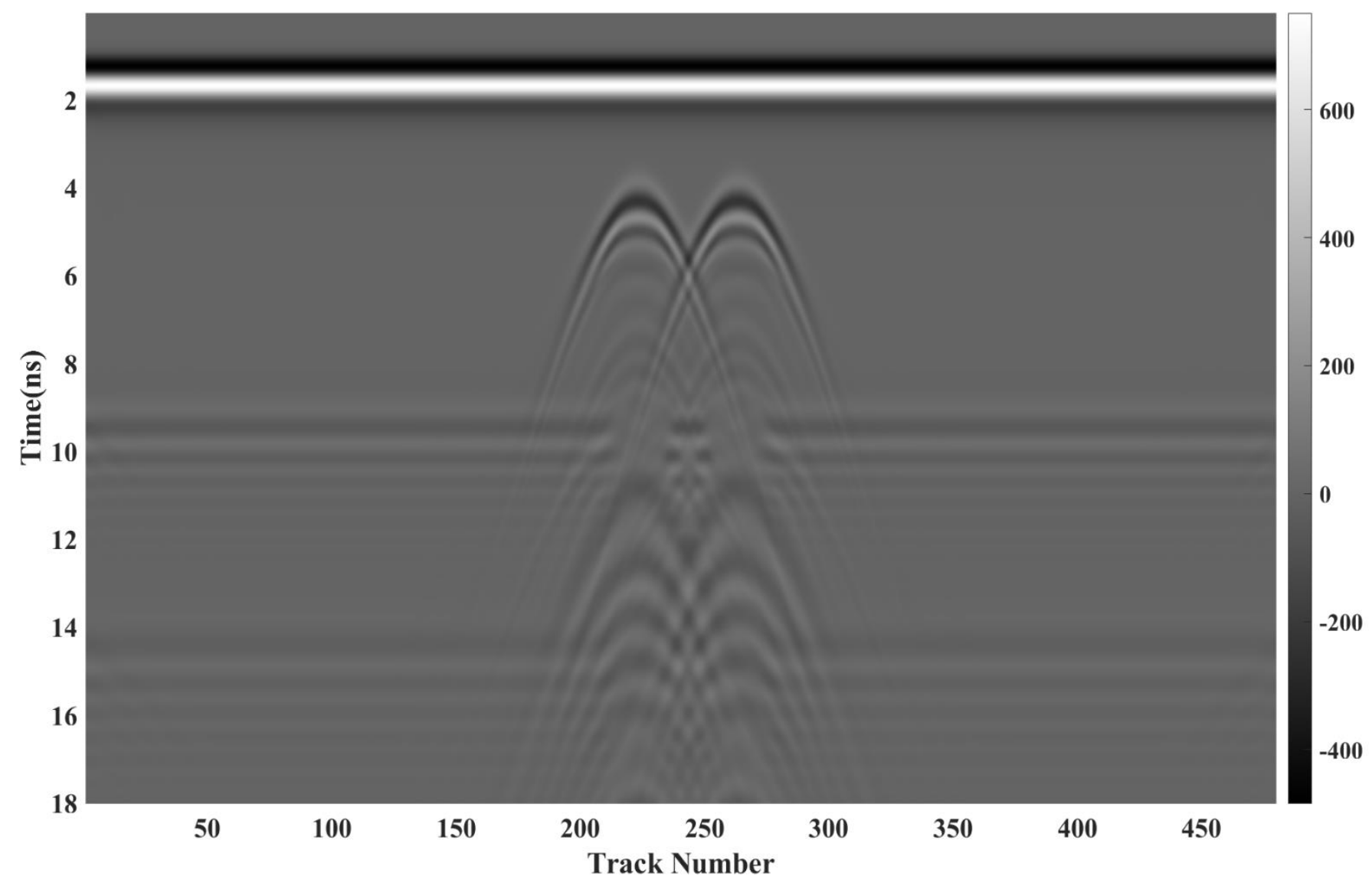

Figure 6. (c) $0.4 \mathrm{~m}$ interval 


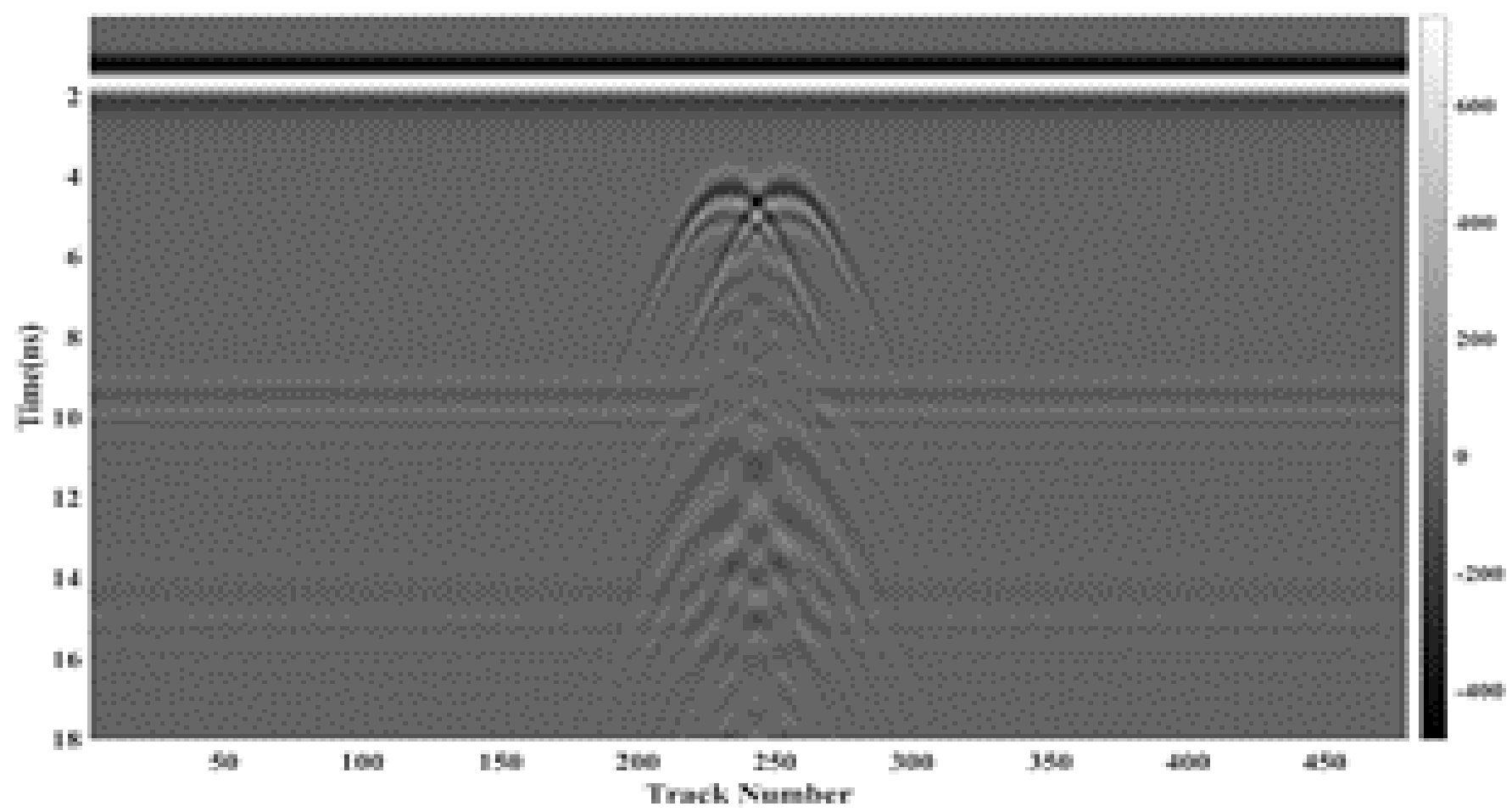

Figure 6. (d) $0.2 \mathrm{~m}$ interval

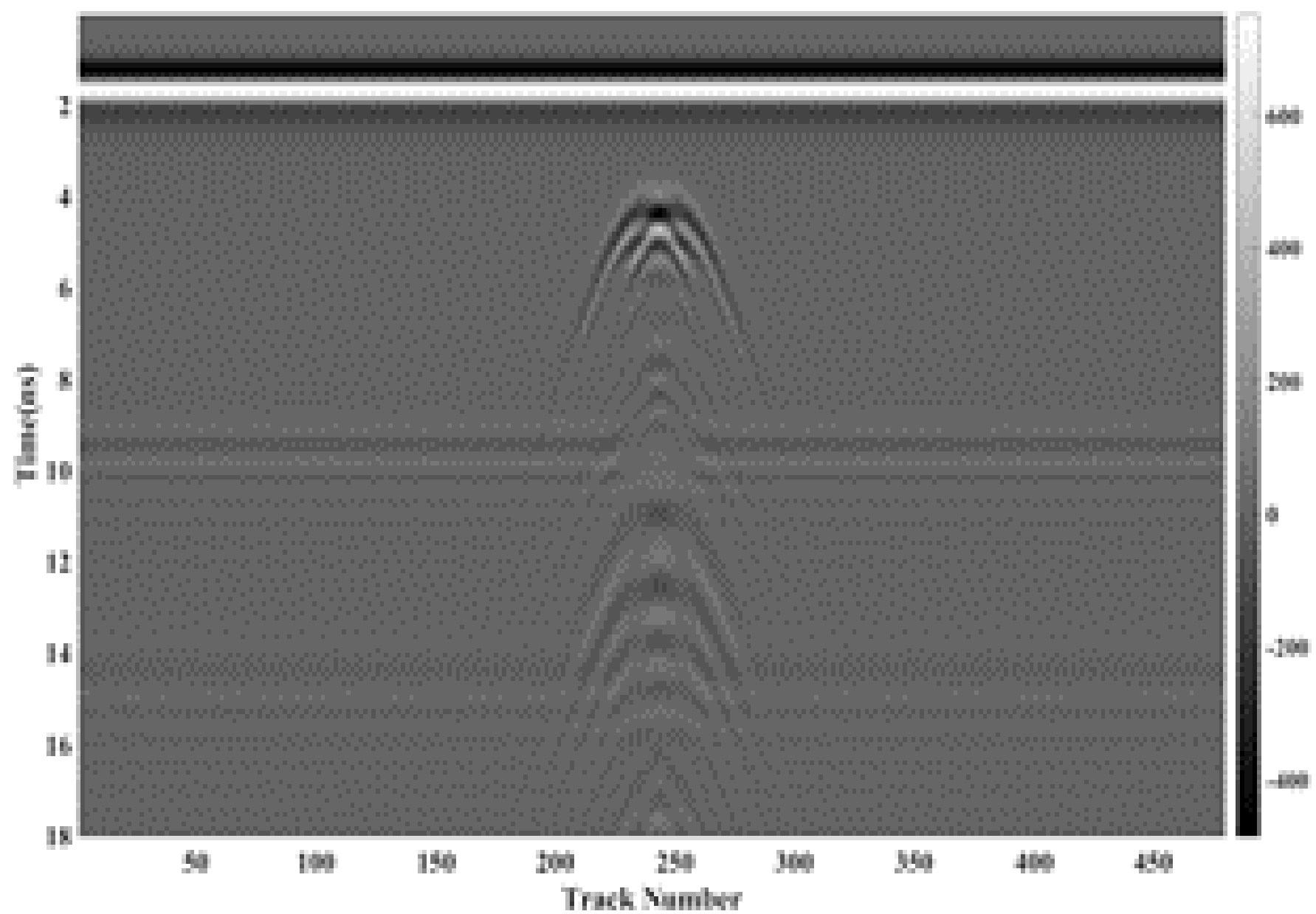

Figure 6. (e) $0.1 \mathrm{~m}$ interval

Figure 6. Forward diagrams of lateral spacing water-bearing anomaly model 
It can be seen from the forward response records of GPR in Figure 6. that the white strips in the figure are direct waves, and the water-bearing anomalies at different positions have hyperbolic reflection, as well as the interfaces between the secondary lining and the primary support, and between the primary support and the surrounding rock. When the two anomalies are far apart, the hyperbola is obvious and easy to distinguish, but when the anomaly interval is reduced to $1 \mathrm{~m}$, the hyperbola tends to intersect, but it is also easy to distinguish. When the interval is $0.4 \mathrm{~m}$, the hyperbola has intersected and can be distinguished, and the two arc tops are easy to distinguish. When the interval is $0.2 \mathrm{~m}$, the hyperbola intersects and there is a strong energy point.

\subsubsection{Cracks model}

The fracture model is set as a rectangle with a thickness of 0.03 and a length of $1 \mathrm{~m}$ in the surrounding rock, with air and water inside. Because the anomaly is located in the deep part, the time window size is changed to $28 \mathrm{~ns}$, and the model and record are shown in Figure 7.

From the forward response records of GPR in Figure 7. (b) and Figure 7. (c), it can be seen that the white strips in the figure are direct waves, and the water-bearing anomalies at different positions have hyperbolic reflection, as well as the interfaces between the secondary lining and the primary support, and between the primary support and the surrounding rock. The results show that the electromagnetic wave response characteristics of the cracks are banded, and the approximate time depth is about 16ns. The band filled with water is larger than that filled by air. The band without filling crack is $16-20 \mathrm{~ns}$, and the band filled by water lasts to $23 \mathrm{~ns}$.

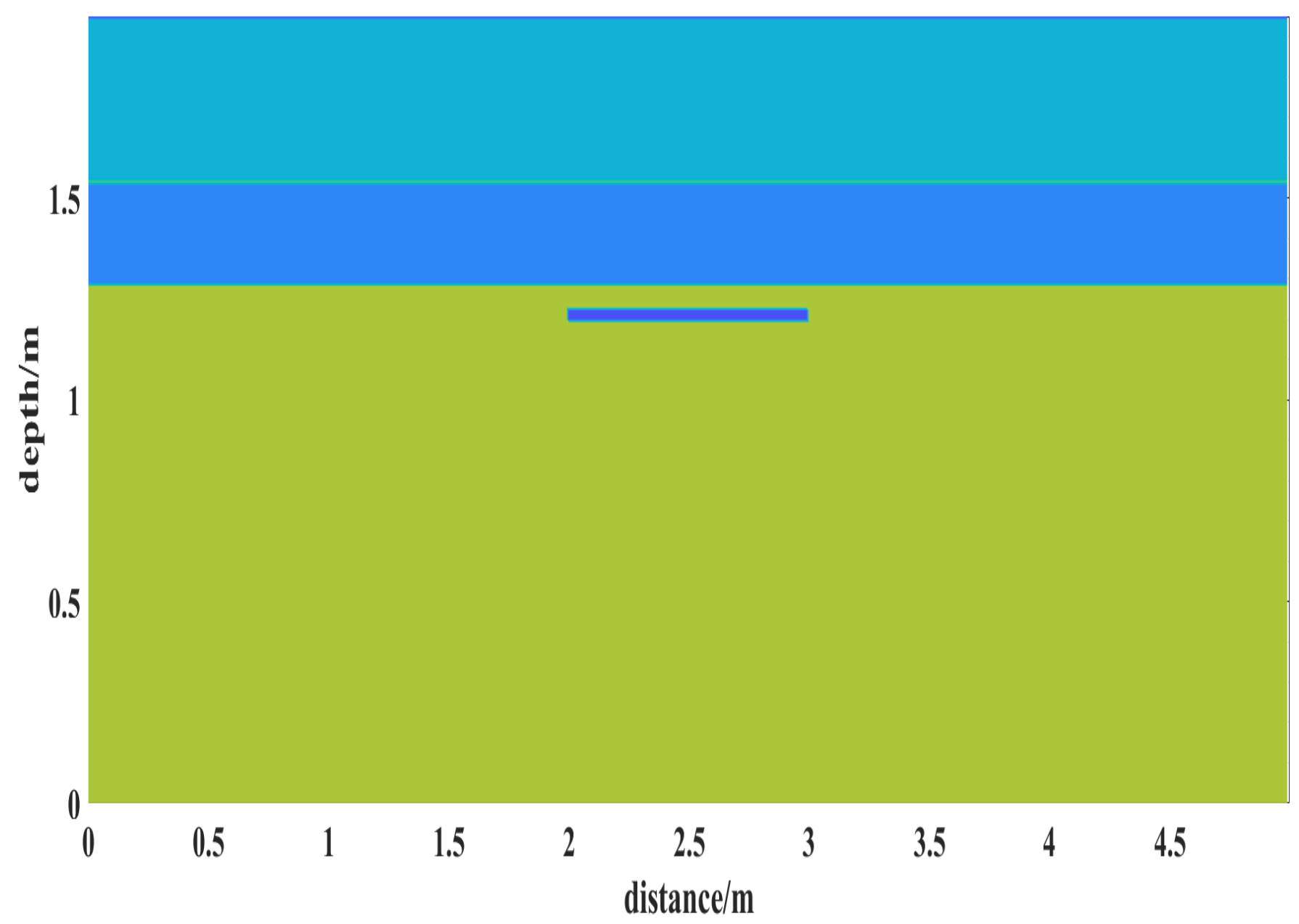

Figure 7. (a) Model 


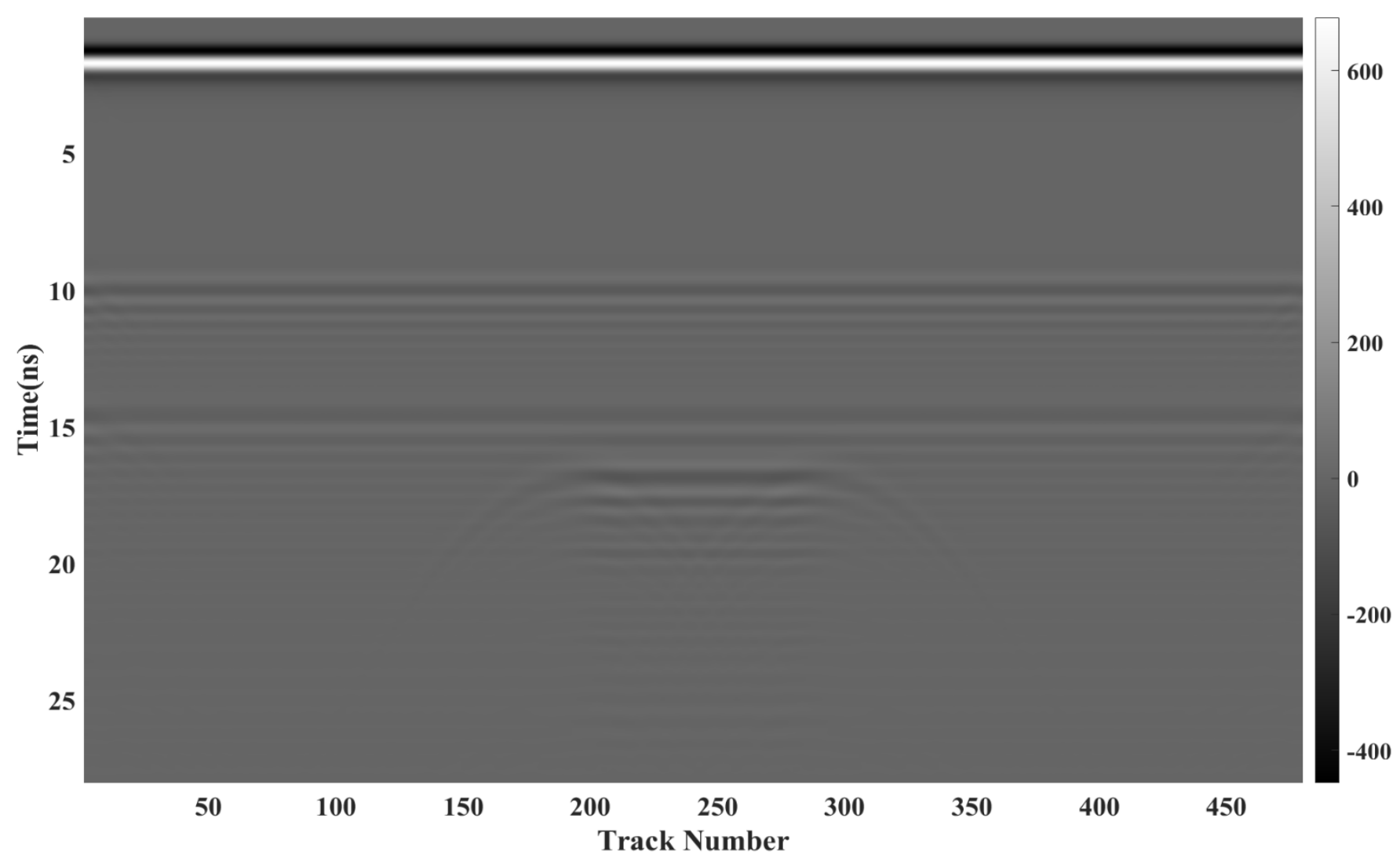

Figure 7. (b) No filling crack model record

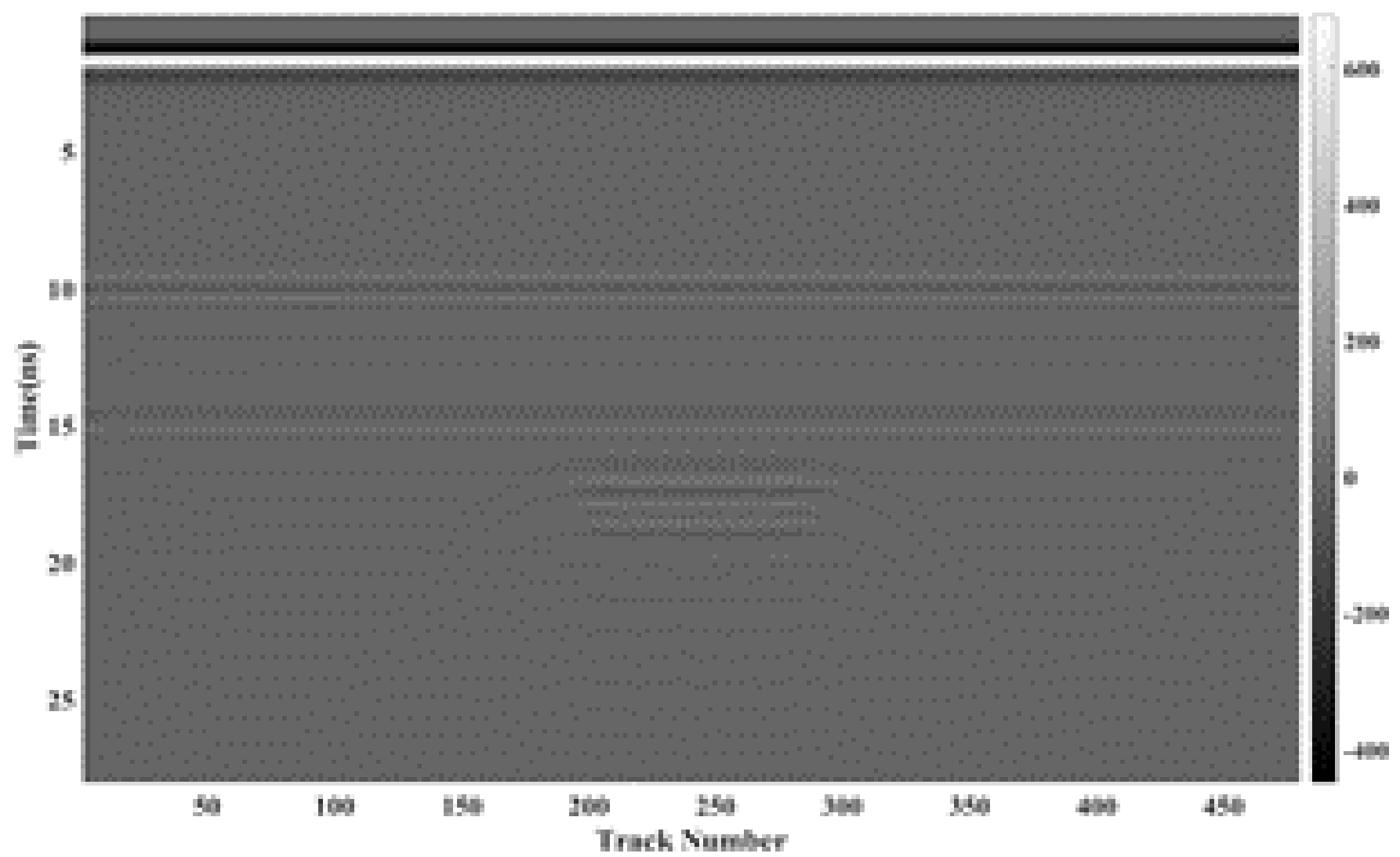

Figure 7. (c) Water-filled crack model record

Figure 7. Forward view of crack model 


\subsubsection{Composite defect models of cavities and irregular cracks in different media}

The model is set as the cavity and water-bearing anomaly in the second lining, and the fracture is filled with air and water. The record is shown in Figure 8.

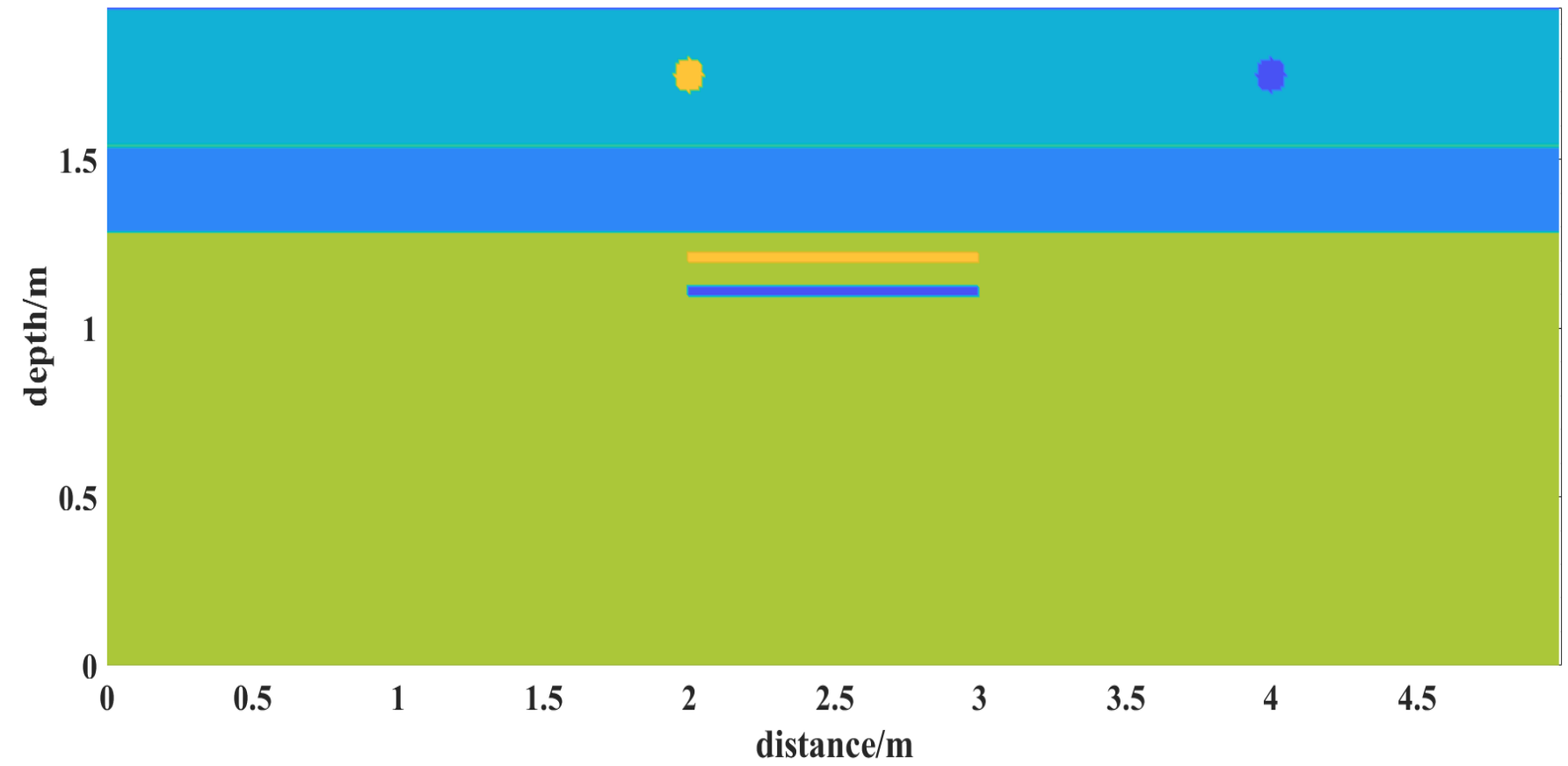

Figure 8. (a) Model

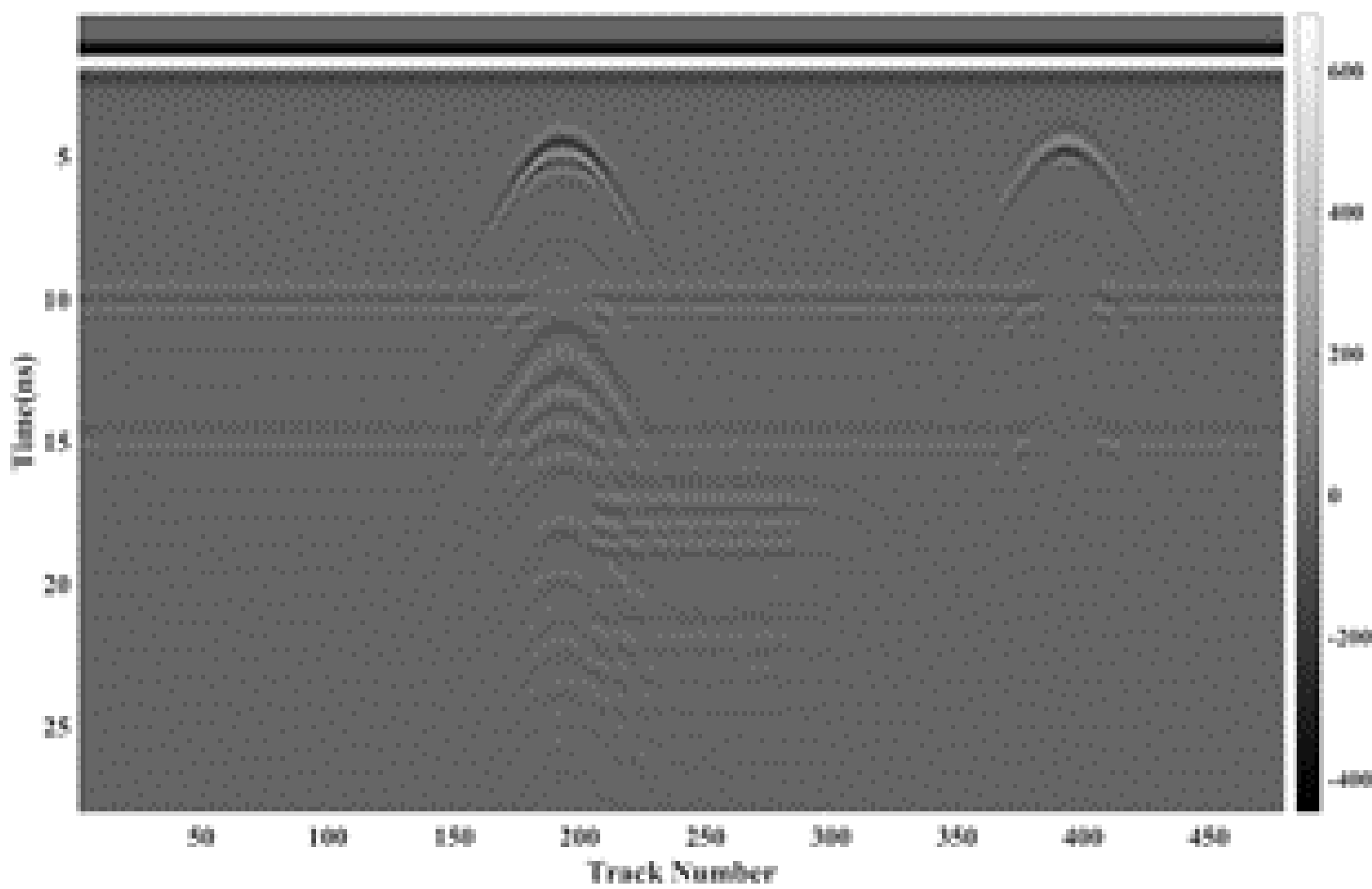

Figure 8. (b) Response record

Figure 8. Forward view of composite model 
From the forward response record of the ground penetrating radar in Figure 8., it can be seen that the white bands in the figure are direct waves, and the interface bands between the second lining and the first support, and the first support and the surrounding rock are obvious. There is a hyperbola at positions 10 and 20 at 4ns, and the hyperbola on the left is abundant and obvious, corresponding to the circular waterbearing abnormality. The hyperbola on the right is felt and the phase of the arc crest at the lower part of the interface is 0 , only at both ends. The hyperbolic tail branch is the corresponding position of the cavity, and the bands at 10-15 are the response characteristics of the cracks. Because of their mixing, the corresponding positions cannot be distinguished.
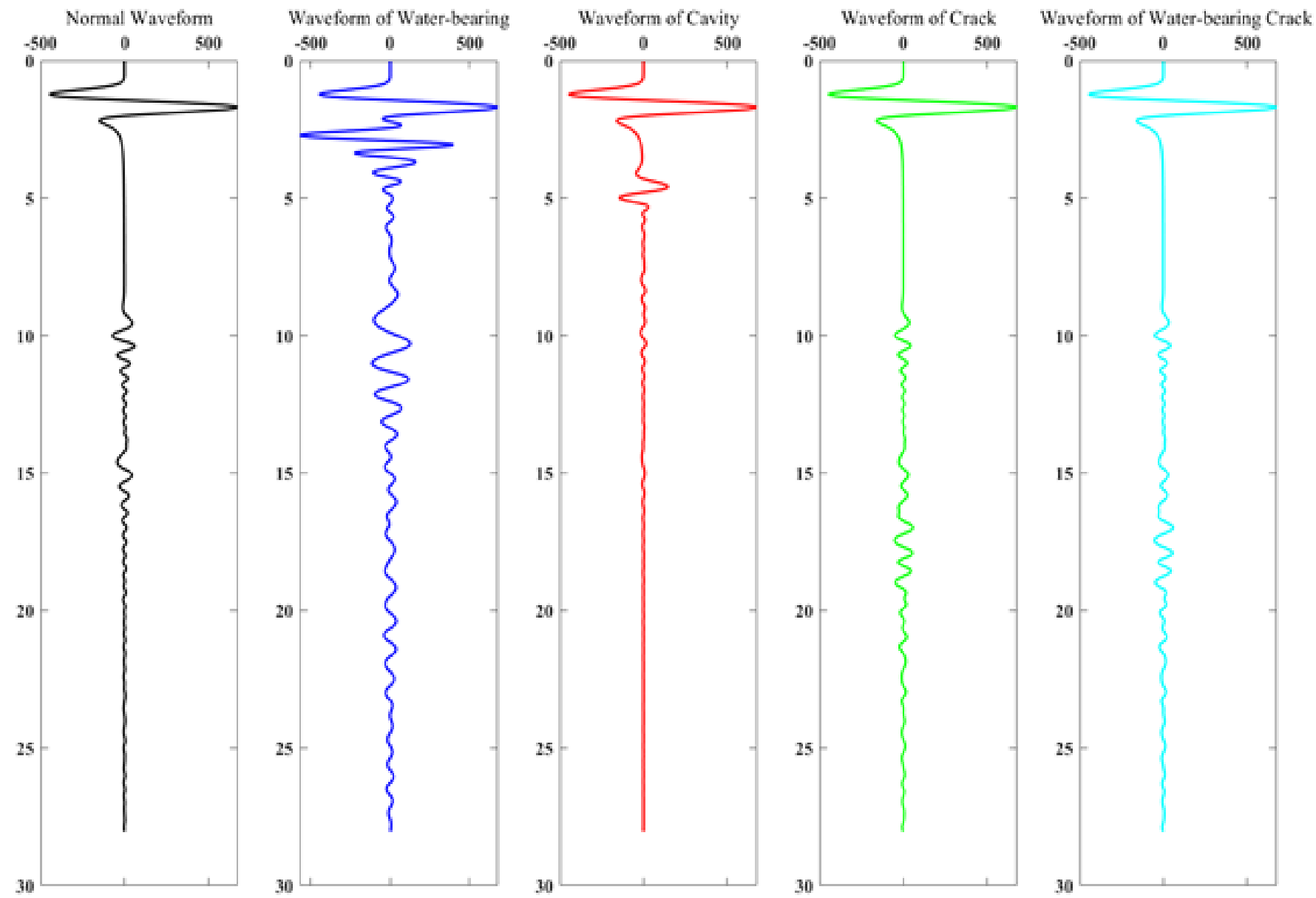

Figure 9. Waveform comparison diagram

It can be seen from the comparison of waveforms in Figure 9. that (a) is a normal tunnel, that is, it does not contain any anomalies. Its waveform has a group of peaks and troughs at $2 \mathrm{~ns}$, which is a direct wave. At 10ns, it is the interface between the second lining and the primary support, and at $15 \mathrm{~ns}$, it is the interface between the primary support and the surrounding rock (b). The figure shows a water-bearing circle in the second lining. The direct wave at $2 \mathrm{~ns}$ is connected with the water-bearing anomaly at $4 \mathrm{~ns}$. The phase value at the interface between the secondary lining and the primary support at 10ns is larger than that in (a). The interface between the primary support and the surrounding rock at $15 \mathrm{~ns}$ has little influence on the waveform, and the lower part of the waveform also has small amplitude oscillation (c). The figure shows a circular cavity in the second lining. Its waveform has a group of peaks and troughs at $2 \mathrm{~ns}$, which is a direct wave. It is easy to distinguish. It can be seen that the cavity does not affect the direct wave and the upper waveform. At 5ns, the cavity is abnormal, but the lower waveform is gentle (d). The waveform of the fracture is similar to that of (a), except that there are peaks and troughs with smaller phase at the crack 
location (e). The figure shows the waveform of water-bearing crack, which is the same as that in (d) figure, except that there are small phase peaks and troughs at the crack location.

\section{Ground penetrating radar identification standard for grouting defects behind tunnel wall}

This paper takes the grouting behind the tunnel wall as the research object, carries out forward simulation, and studies the characteristics of different types of abnormal ground penetrating radar images. Through theoretical analysis, the method and characteristic standard of using ground penetrating radar to detect the tunnel wall and determine the grouting quality are put forward. The radar characteristics of cavities, waterbearing cavities, cracks, and water-bearing cracks are analyzed, and the basic characteristics of ground penetrating radar detection and recognition of grouting behind the tunnel wall are explained. The morphological features of cavities in ground penetrating radar images are usually composed of many hyperbolic strong reflection waves. Based on the ground penetrating radar forward record in Chapter 2, the identification standards for defective ground penetrating radar are summarized as follows in Table 3.:

Table 3. Defect identification standard table

\begin{tabular}{lll}
\hline \multicolumn{1}{c}{ Grouting defects } & \multicolumn{1}{c}{ Forward record } & \multicolumn{1}{c}{ Waveform graph } \\
\hline Cavity & $\begin{array}{l}\text { Hyperbola, no obvious multiples in } \\
\text { the lower part }\end{array}$ & $\begin{array}{l}\text { The peak amplitude is about 200, no } \\
\text { influence on the waveform }\end{array}$ \\
Water-bearing cavity & $\begin{array}{l}\text { Hyperbola with multiple waves in } \\
\text { the lower part }\end{array}$ & $\begin{array}{l}\text { The peak amplitude is about 500, which } \\
\text { has a greater impact on the waveform } \\
\text { crack }\end{array}$ \\
Bands & The peak amplitude is about 100
\end{tabular}

According to the characteristics of reflected wave group, phase axis, and waveform of the radar image, the position, and size of interface, cavity, and crack are determined. The direct wave is the wave that directly reaches the receiving antenna along the ground without energy loss, so it is usually the white band with the largest amplitude at the time depth of 2ns; According to the GPR response records, the boundaries between the secondary lining and the primary support, and between the primary support and the surrounding rock are divided into four bands, and their amplitudes are about 100; When the cavity anomaly is located in the second lining, the GPR image is a reflection hyperbola, and the phase at the interface of the corresponding position of the arc top decreases, and there are hyperbolic tail branches on both sides; When there is a waterbearing circular anomaly in the secondary lining, the GPR image is a reflection hyperbola, and the phase at the interface corresponding to the arc top increases, and there is a complete hyperbola at the bottom; When there is a fracture in the surrounding rock, the GPR response record is a short strip with the same length as the fracture, the peak amplitude is about 100, and the duration is 4ns. When there is water in the fracture, the difference between the characteristics and the fracture is that the duration is $8 \mathrm{~ns}$.

\section{Conclusion}

In order to effectively guide the quality detection of tunnel wall grouting based on detection radar, based on the finite difference time domain method, the forward modeling of tunnel wall grouting defects is carried out by using the difference of dielectric constant. Four kinds of abnormal conditions including round cavity, 
water-bearing anomaly, rectangular fracture, and water-bearing fracture are simulated.

(1) The forward record of GPR shows that the reflected image of a direct wave is characterized by a white band with strong amplitude; The interface between primary support and secondary lining, primary support and surrounding rock are also banded; The difference is that the phase of the lower part of the radar image of the cavity anomaly is zero, and there are only hyperbolic tail branches on both sides, while the water-bearing anomaly also has obvious hyperbolic features on each interface; The reflection characteristics of rectangular fractures are banded, and the abnormal range of waterbearing fractures in the radar image is larger than that of air. The above abnormal radar reflection record law can lay the foundation for the subsequent explanation.

(2) When two anomalies exist at the same time and the interval is large, the hyperbolas of each anomaly do not affect each other and are easy to identify; however, when the anomaly interval is shortened, the hyperbolas are easy to cross and difficult to distinguish.

\section{Disclosure statement}

The author declares no conflict of interest.

\section{References}

[1] Yang B, 2016, Research on Establishing All-round and Three-dimensional Quality Protection of Oil Pipeline. China Petroleum and Chemical Standard and Quality, 36(12),29-29+40.

[2] Xiao P, Liu C, Sun K, 2019, Study on Grouting Treatment of Water Inrush and Mud Inrush Disaster in Expressway Tunnel. Transpo World, (9): 103-104.

[3] Ding Z, 2004, Research on Laws of Surface Lift and Subsidence during Grouting at the Back of Tunnel Wall in the Shanghai Subway. Coal science research institute.

[4] Lin C, Wang X, Li Y, et al., 2020, Forward Modelling and GPR Imaging in Leakage Detection and Grouting Evaluation in Tunnel Lining. KSCE Journal of Civil Engineering, 24(1): 278-294.

[5] Xie X, Zhai J, Zhou B, 2021, Back-Fill Grouting Quality Evaluation of the Shield Tunnel Using Ground Penetrating Radar with Bi-Frequency Back Projection Method. Automation in Construction, 121: 103435.

[6] Bai M, Chen Y, Wang C, et al., 2018, Radar Spectral Analysis and Evaluation of the Effect of Grouting Treatment in Karst Caves and Soil Caves. Environmental Earth Sciences, 77(24): 1-12.

[7] Du J, Huang H, Xie X, 2007, Simulation of GPR Detecting of Grouting Materials Behind Shield Tun nel Segments. Chinese Journal of Geotechnical Engineering, 29(2): 243-248.

[8] Sun Z, et al., 2013, The Tunnel Detection Forward Numeral Simulation and Measured Data Analysis based on GPRMax. Chinese Journal of Engineering Geophysics, 10(5): 730-735.

[9] Du J, Huang H, Xie X, 2005, Research on the Simulation Examination about GPR Detection of Grounting Material Shield Tunnel Segment. Chinese Journal of Underground Space and Engineering, (6): 817-820.

[10] Zeng C, et al., 2005, GPR Forward Simulation for Shield Tunnel Conditions Based on theConsistent Information Removal Method. Moden Tunnelling Technology, 52(4): 173-178.

[11] Zeng ZF. et al., 2006, Principle and Application of Ground Penetrating Radar. Beijing: Science Press.

[12] Bai B, Zhou J, 2001, Development and Application Status of Ground Penetrating Radar Testing 
Technology. Chinese Journal of Rock Mechanics and Engineering, (4): 527-531.

[13] Guo S, et al., 2019, Ground Penetrating Radar Multi-Profile Integrated Interpretation Method and Application. Progress in Geophysics, 34(5): 2022-2029.

[14] Xiao D, Li W, Guo P, 2015, The Tunnel Lining Detection Numerical Simulation based on GPRMax and its Application. Geophysical and Geochemical Exploation, 39(4): 855-859.

[15] Xu H, Liu J, Fan C, et al., 2013, Forward Modeling of Tunnel Lining Diseases Ground Penetrating Radar Wave Field and Characteristics Analysis. Journal of Central South University (Science and Technology), 44(11): 4581-4587.

[16] Wang F, Xiao G, Yin J, 2003, Application of Ground Probing Radar to Detection of Lining Concrete Quality. Rock and Soil Mechanics, 2003(S1): 183-185.

[17] Li J, Guo C, Wang F, et al., 2007, The Summary of the Surface Ground Penetrating Radar Applied in Subsurface Investigation. Progress in Geophysics, (2): 629-637.

[18] Feng D, Dai Q, He J, et al., 2006, Finite Difference Time Domain Method of GPR Forward Simulation (English). Progress in Geophysics, (2): 630-636.

[19] Yee KS, 1966, Numerical Solution of Initial Boundary Value Problems Involving Maxwell's Equations in Isotropic Media. IEEE Transactions on Antennas \& Propagation, 14(3): 302-307.

[20] Lv N, 2020, Analysis of FDTD based Ground Penetrating Radar Forward Simulation. Journal of Luoyang Institute of Science and Technology (Natural Science Edition), 30(4): 63-68, 74.

[21] Li Z, Pu D, Zhong M, 2019, Contrastive Study on Waveform Characteristics between Ground Penetrating Radar Simulation and Detection Example in Karst Structure of Highway Tunnel. Technology of Highway and Transport, 35(2): 110-117. 